Huayna Terraschke ${ }^{1}$ / Merrit Rothe ${ }^{1}$ / Patric Lindenberg ${ }^{1}$

\title{
In situ monitoring metal-ligand exchange processes by optical spectroscopy and X-ray diffraction analysis: a review
}

\author{
${ }^{1}$ Institute of Inorganic Chemistry, Christian-Albrechts-Universität zu Kiel, Max-Eyth-Str. 2, 24118 Kiel, Germany, E-mail: \\ hterraschke@ac.uni-kiel.de
}

\begin{abstract}
:
Knowledge about the mechanisms involved in the structural development of solid materials at the atomic level is essential for designing rational synthesis protocols for these compounds, which may be used to improve desired technical properties, such as light emission, conductivity, magnetism, porosity or particle size, and may allow the tailored design of solid materials to generate the aforementioned properties. Recent technological advancements have allowed the combination of synchrotron-based in situ X-ray diffraction (XRD) with in situ optical spectroscopy techniques, providing researchers with remarkable opportunities to directly investigate structural changes during synthesis reactions. Among the various available methods to measure optical properties, in situ luminescence, UV/Vis absorption, and light transmission spectroscopies are highlighted here, with in situ luminescence being subdivided into in situ luminescence analysis of coordination sensors (ILACS) and time-resolved laser fluorescence spectroscopy (TRLFS). This article consists of a review of 122 references exploring various aspects of in situ analyses, with particular emphasis on the use of XRD-combined techniques in the study of metal-ligand exchange processes during the formation, phase transitions and decomposition of solid materials, including complexes, coordination polymers, metal-organic frameworks, nanoparticles and polyoxo- or chalcogenide metallates. We will then conclude with an exploration of future trends in this exciting research field.
\end{abstract}

Keywords: in situ luminescence, in situ X-ray diffraction, metal-ligand exchange, reaction mechanism, synchrotron radiation

DOI: $10.1515 /$ revac-2017-0003

Received: February 7, 2017; Accepted: June 25, 2017

\section{Introduction}

Understanding the mechanisms behind the changes in the immediate surroundings of metal ions in metalligand exchange processes during, for example, the formation, phase transition or decomposition of solid compounds is essential for the development of a number of materials which are used in a large variety of fields, including lighting, bioimaging, catalysis, gas storage and sensors, among many others. Examples of these materials include hybrid organic-inorganic complexes (Terraschke et al., 2016), coordination polymers (CP, Schweinefuß et al. 2014), metal-organic frameworks (MOFs, Yeung et al. 2016), polyoxometallates (POMs, Antonova et al., 2012), chalcogenide metallates (Seidlhofer et al., 2012) and inorganic complexes, which may be applied as precursors or structure-directing agents for the formation of metallic nanoparticles (NPs) (St. John et al., 2013). Despite the high complexity of these materials, most of the articles reporting their discovery and optimization are limited to analysis via ex situ techniques.

In traditional ex situ characterization methods, the product is analyzed after the synthesis is complete. This provides researchers with no information about the influence of synthesis parameters on the reaction and, even more critically, leaves key intermediate products undiscovered (Pienack \& Bensch, 2011). Not only may these intermediates possess technically interesting properties in their own right, their characterization may provide important information concerning the phase transitions necessary for generating the final product, allowing for the development of more efficient synthesis protocols and the production of fewer undesired side products.

In principle, analysis of intermediaries using $e x$ situ techniques is possible but requires individual analyses of multiple small samples which have been removed from the reactor at pre-determined times. Unfortunately, 
such $e x$ situ analysis presents several aggravating drawbacks. First, removing samples during synthesis might influence the relative concentrations of reactants sufficiently to influence all subsequent molecular interactions and, ultimately, alter aspects of the final reaction product. Moreover, the nature of the intermediates removed from the reaction may be misrepresented by these analyses, as the samples must be treated, quenched, washed and dried before analysis, introducing several sources of error. Incomplete quenching may allow the reaction to continue after removal of the sample from the reaction vessel, altering the composition of the analyzed compound from those which remain in the reactor. Washing steps may produce hydrates, impairing the isolation of any present anhydrous compounds. Conversely, drying may remove water molecules from crystal lattices, hindering the isolation of intact hydrated intermediates. Additionally, ex situ techniques provide only discrete snapshots of the reaction, rather than following the complete process, which massively reduces the time resolution of the analyzed data. Together, these sources of error make it impossible to be certain that the analysis of the isolated samples paints an accurate picture of the phenomena occurring inside the reactor. Moreover, these methods are very time consuming and expensive due to the preparation and analysis of many individual samples.

In situ characterization techniques provide solutions to many of the above-mentioned complications accompanying ex situ methods. In situ measurements are continuously recorded during the reaction, allowing the detection of even short-lived intermediates and phase transitions without removing any material from the reaction. This allows for a much clearer understanding of reaction processes under real reaction conditions, including the kinetics of desired product formation, facilitating real-time adjustment of synthesis parameters. Additionally, in situ methods are markedly less time intensive than ex situ procedures. For these reasons, in situ characterization techniques are essential for accurately elucidating mechanisms of chemical reactions (Pienack \& Bensch, 2011).

For the formation of metal-based materials in solution, key factors influencing the formation of the final product are the metal-ligand exchange processes (Braga et al., 2009). For many metal-based materials, this process begins by dissolving a metal salt in solution. The anionic units occupying the metal coordination environment within the salt are hereby exchanged for solvent molecules, creating a solvation shell. This is usually followed by a desolvation process, whereby the solvent molecules are exchanged for the newly introduced (anionic) ligand units to form the final product. In detail, the formation of hybrid materials can proceed in three different ways. The most common formation mechanism involves substitution reactions, where ligands in close proximity to the complex and with higher nucleophile strength substitute existing ligands, creating a kinetically more stable complex (Gade, 2010). This is often the case for aqua complexes, as water molecules are easily replaced by other common ligands. Generally, one of three different mechanisms mediate ligand exchange during a substitution reaction: the dissociative mechanism (D) (exit of old ligand, decrease in the coordination number, entry of new ligand), associative mechanism (A) (entry of a new ligand, increase in the coordination number, exit of the old ligand) or exchange mechanism (I) (simultaneous process) (Gade, 2010). The activation energy of substitution reactions depends on electronic and steric characteristics of the entering and leaving ligands. The second mechanism for complex formation is the intramolecular transformation of a complex. In this process, the existing ligands rotate and change their positions, forming new bonds and a completely new complex. The final mechanism of complex formation relies on the ability of metal complexes to transfer electrons between their metal centers. This is an important characteristic for bioinorganic reactions, including, for example, the electron transfer in plant cells during photosynthesis. This redox reaction may occur via one of two mechanisms: an outer-sphere or an inner-sphere transfer. During the outer-sphere mechanism, electron transfer takes place without any modification of the ligand sphere. During the inner-sphere mechanism, on the other hand, a precursor complex is formed and electron transfer is mediated via a bridging ligand (Gade, 2010).

Naturally, many rounds of ligand exchange processes can occur if the product is not directly formed, but rather requires the formation of one or more intermediate complexes during its synthesis. For some polymorphic materials, these exchanges can be extensive with numerous metastable polymorphs being formed prior to the formation of the thermodynamically stable phase. The complex chain of events involved in these processes can be very challenging or impossible to understand or predict without properly elucidating the nature of the interaction between metal units and ligands during the formation of the crystal structure. This principle was recently underscored by several studies investigating the formation of metallic NPs, including Pt (St. John et al. 2013), PdZn (Veligzhanin et al. 2013), PtPd (Zadesenets et al. 2013) and Au NPs (Yao et al. 2010), which demonstrated how the generation of an initial metal complex drastically influences formation and properties of the final particles (St. John et al. 2013). Indeed, these studies revealed how reaction conditions could alter the monodispersibility of early nucleation centers, thereby drastically altering crystal growth and the functionality of the obtained product.

Numerous powerful in situ characterization methods have been well described in the literature. These include the pair distribution function (Jensen et al., 2012; Mi et al., 2015; Saha et al., 2015), X-ray absorption (XAS) (Bauer \& Bertagnolli, 2009; Hollingsworth et al., 2014; Keating et al., 2013), Raman (Cornel, Lindenberg \& Maz- 
zotti, 2008; Vergote et al., 2002), infrared (IR) (Kubanek et al. 2004; 2005), nuclear magnetic resonance (Férey et al., 2014; Haouas et al., 2012; Vistad et al., 2003) and mass spectrometry (Pelster, Schrader \& Schüth, 2006; Schaack et al., 2009). The in situ application of these techniques has been previously summarized elsewhere (Pienack \& Bensch, 2011). The present article focuses specifically on recent developments on the use of in situ X-ray diffraction (XRD) analysis and optical spectroscopies for monitoring metal-ligand exchange processes during the formation of metal-based materials.

In situ XRD delivers very valuable information about temporal evolution in the atomic arrangement during complex formation, from nucleation through crystal growth, including intermediate formation during crystallization processes. This method does not, however, provide any information about amorphous materials, ions in solution, very small crystallites and side products present at very low concentration that are rarely detected. In situ XRD in solution requires the use of synchrotron radiation to penetrate reactor glass walls and solvent bulk volume, which restricts its applicability. To close these gaps, in situ optical spectroscopy measurements can be simultaneously carried out (Terraschke et al. 2016). As discussed in Section "In situ monitoring of optical properties", in situ UV/Vis absorption, light transmission and luminescence spectroscopy (reviewed here for the first time) are some of the most practical complementary in situ techniques.

Before we discuss these complementary optical spectroscopy methods, however, we will first summarize the available in situ characterization methods applied for analyzing metal-ligand interactions during formation of hybrid materials (Section "General overview of applied in situ characterization methods for monitoring metalligand exchange processes"). We will then explore the application of synchrotron-based in situ XRD (Section "In situ XRD analysis") for a broad range of materials, review a number of literature examples involving the simultaneous application of multiple in situ methods (Section "Technical aspects of multiple combinations of in situ characterization methods") and conclude by exploring future trends within this exciting field of research (Section "Conclusions"). Because the literature on the application of in situ analysis techniques is growing rapidly, only the most relevant works have been selected for review here. The reader is encouraged to reference other reviews for general overviews of in situ characterization techniques (Jensen et al., 2014; Pienack \& Bensch, 2011; Stawski \& Benning, 2013; Walton \& Millange, 2016), metal-ligand exchange kinetics of Pt and Ru complexes (Reedijk, 2008), application of in situ X-ray scattering studies for monitoring the synthesis of inorganic-organic hybrid thiometallates (Seidlhofer, Pienack \& Bensch, 2010) and the construction of reactors for performing in situ XRD studies (O'Hare et al., 1998; Walton \& O'Hare, 2000).

\section{General overview of applied in situ characterization methods for monitoring metal-ligand exchange processes}

As discussed above, metal-ligand exchange processes culminating in the formation of metal-based materials, such as complexes, $\mathrm{CP}, \mathrm{MOF}$, POMs or chalcogenide metallates, present a high degree of complexity and should be, therefore, primarily characterized by in situ analysis techniques. Table 1 summarizes the most common in situ methods for monitoring these processes, with selected examples from the literature. In situ monitoring of optical properties, such as UV/Vis absorption spectroscopy, luminescence spectroscopy and, the relatively new method, light transmission and in situ XRD are discussed in detail in the next sections.

Table 1: Examples of applications for various in situ measurement techniques for monitoring metal-ligand exchange processes.

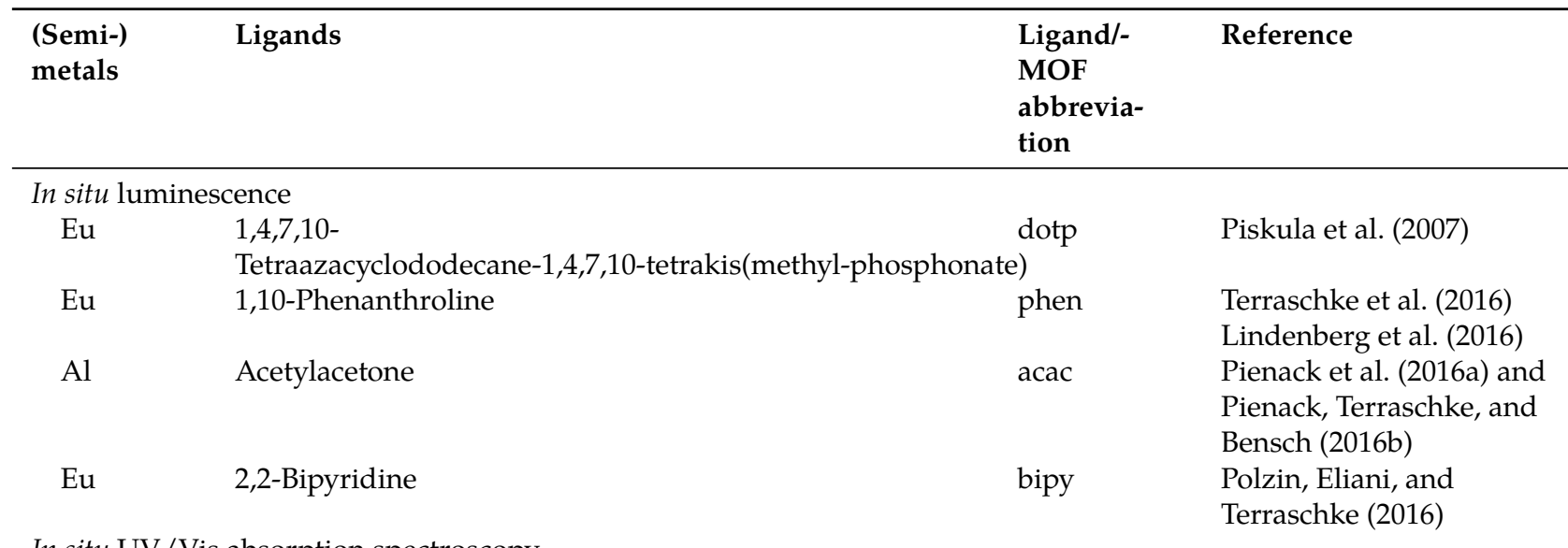

In situ UV/Vis absorption spectroscopy 


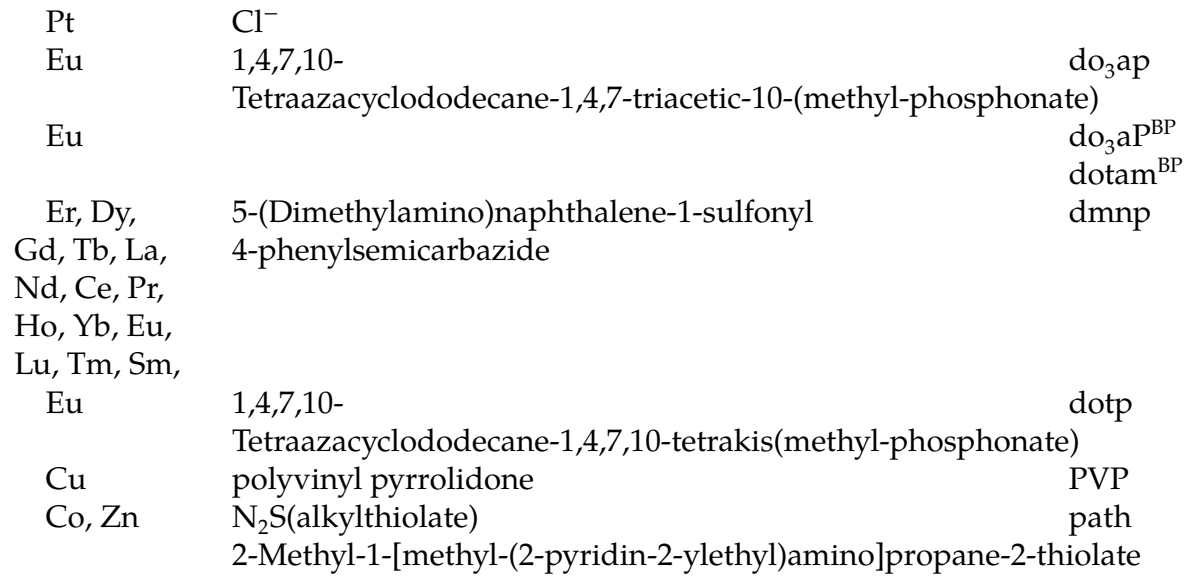

Light transmission

Al Acetylacetone

In situ (energy dispersive) X-ray diffraction

$\mathrm{Cu} \quad$ 1,3,5-Benzenetricarboxylate

$\mathrm{Cu} \quad 4,4^{\prime}, 4^{\prime \prime}$-Benzene-1,3,5-triyl-tris(benzoate)

Li 2,5-Thiophenedicarboxylate

Co, $\mathrm{Ni}$ 2,5-Dioxoterephthalate

Li Tartrate

Fe 1,10-Phenanthroline

$\mathrm{Yb} \quad$ Benzene-1,4-dicarboxylate

$\mathrm{Pt}, \mathrm{Zr} \quad$ 2,2'-Bipyridine-5,5'-dicarboxylate

Biphenyl dicarboxylate

Ge 1,4-Diaminobutane

$\mathrm{Zn}, \mathrm{Co}, \mathrm{Ni} \quad$ 1,4-Benzenedicarboxylate

1,4-Diazabicyclo-[2.2.2] octane

Co 2,6-Naphthalenedicarboxylate dimethylformamide

$\mathrm{Na}, \mathrm{Al}$

$\mathrm{PO}_{4}{ }^{3-}, \mathrm{H}_{2} \mathrm{O}$

Tris(2-aminoethyl)amine

Sn Tetramethylammonium

$\mathrm{Nd} \quad$ 1,3,5-Benzenetricarboxylate

$\mathrm{Fe}, \mathrm{Pt} \quad$ Pyrazine

$\mathrm{Fe}, \mathrm{Pt} \quad$ Pyridine

$\mathrm{CN}^{-}$

$\mathrm{Pd}, \mathrm{Zn} \quad$ Acetate

Rh, Pt $\quad \mathrm{NH}_{3}, \mathrm{Cl}^{-}$

La, Ce, Pr, Phosphonatobutanesulfonate

$\mathrm{Nd}, \mathrm{Sm}, \mathrm{Eu}$,

$\mathrm{Gd}$

Ir Imidazolate

Co, Sn Tris(2-amino-ethyl)amine

Mn Thioantimonate

1,3-Di-aminopropane

N-Methyl-1,3-diaminopropane

Diethylenetriamine

$\mathrm{Ge} \quad \mathrm{OH}^{-}$

1,2-Diamino-propane

$\mathrm{V}, \mathrm{Sb} \quad$ 1-(2-Amino-ethylpiperazine)

$\mathrm{Fe}, \mathrm{Sn} \quad$ Tris(2-aminoethyl)amine

$\mathrm{Cu}, \mathrm{Sn} \quad$ 1,5-Diazabicyclo[4.3.0]non-7-ene acac

Yao et al. (2012)

Táborsky et al. (2007)

Procházková et al. (2016)

Riahi et al. (2009)

Piskula et al. (2007)

Nishimura et al. (2010)

Chang et al. (2002)

Pienack et al. (2016a) and Pienack, Terraschke, and Bensch (2016b)

btc

HKUST-1

btb

MOF-14

tdc

dhtp

CPO-27

phen

bdc

bpydc

Millange et al. (2010)

Millange et al. (2010)

El Osta et al. (2012)

El Osta et al. (2013)

Yeung et al. (2016)

Lei et al. (2002)

Wu et al. (2016a)

Øeien et al. (2015)

UiO-67

bdc

dabco

ndc

DMF

tren

MIL-74

tma

btc

$\mathrm{pz}$

py

Inge et al. (2012)

Wu et al. (2016b)

Moorhouse, $\mathrm{Wu}$, and

O'Hare (2016)

Loiseau et al. (2004)

Francis et al. (1996)

Gustafsson et al. (2008)

Otsubo et al. (2012)

Haraguchi et al. (2016)

Veligzhanin et al. (2013)

Shubin, Korenev, and

Sharafutdinov (2006)

Feyand et al. (2010)

im

Schweinefuß et al. (2014)

tren

Kiebach et al. (2006)

dap Engelke et al. (2003)

mdap

dien

2-dap

Kiebach et al. (2005)

aep

tren

Antonova et al. (2012)

Seidlhofer et al. (2012)

Pienack, Näther, and

Bensch (2009) 


\begin{tabular}{|c|c|}
\hline Mn & 1,3,5-Benzenetricarboxylate \\
\hline $\mathrm{Cu}$ & Phosphonosulfonate \\
\hline \multirow[t]{3}{*}{$\mathrm{Zn}$} & 2-Aminoethylphosphonate \\
\hline & 3-Aminopropylphosphonate \\
\hline & 4-Aminobutylphosphonate \\
\hline \multirow[t]{3}{*}{$\mathrm{Bi}$} & Pyromellitate \\
\hline & Trimellitate \\
\hline & Trimesate \\
\hline $\mathrm{Ca}$ & Aminomethylphosphonates \\
\hline $\mathrm{Cu}$ & $\begin{array}{l}\text { Bis(2-carboxyethylgermanium } \\
\text { sesquioxide) }\end{array}$ \\
\hline $\mathrm{Ca}, \mathrm{Ni}$ & Phosphonocarboxylate \\
\hline $\mathrm{Al}$ & 1,4-Cyclohexanedicarboxylate \\
\hline $\mathrm{Al}$ & Terephthalate \\
\hline
\end{tabular}

In situ $\mathrm{pH}$ measurement

$\mathrm{Al} \quad$ Acetylacetone

Eu 1,10-Phenanthroline

Eu 2,2-Bipyridine

In situ conductivity

$\mathrm{Eu}$ 1,10-Phenanthroline

Eu 2,2-Bipyridine

In situ redox potential

$\mathrm{Al} \quad$ Acetylacetone

In situ infrared spectroscopy

Fe 2,6-Bis(2-mercaptophenylthio-methyl)-4-R-pyridine)

$\mathrm{Al} \quad$ Acetylacetone

$\mathrm{Eu}$

1,10-Phenanthroline

$\mathrm{Ni}$

$\mathrm{CO}$

$\operatorname{Re}$

$\mathrm{H}^{+}$

Tripodal polyphosphane

In situ Raman spectroscopy

$\mathrm{Np} \quad \mathrm{O}^{2-}, \mathrm{Cl}^{-}, \mathrm{H}_{2} \mathrm{O}$

In situ optical microscopy

$\mathrm{Pb} \quad \mathrm{DMF}, \mathrm{DMSO}$

In situ X-ray absorption (XAS)

$\mathrm{Pd}, \mathrm{Ir} \quad \mathrm{NH}_{3}, \mathrm{Cl}^{-}$

$\mathrm{Pd}, \mathrm{Zn} \quad$ Acetate

$\mathrm{Au} \quad \mathrm{Cl}^{-}$

$\mathrm{Cu}$ 2,9-Dimethyl-1,10-phenanthroline

Co, Sn Tris(2-amino-ethyl)amine

In situ X-ray photoelectron spectroscopy (XPS)

$\begin{array}{ll}\mathrm{Pd}, \mathrm{Ir} & \mathrm{NH}_{3}, \mathrm{Cl}^{-} \\ \mathrm{Cr} & \mathrm{CN}^{-}\end{array}$

In situ small angle and wide angle $\mathrm{X}$-ray scattering

$\mathrm{Pd}, \mathrm{Sn} \quad \mathrm{Cl}^{-}$

In situ photoemission spectroscopy (PES)

Pt, Pd Oxalate

In situ dynamic light scattering (DLS)

$\mathrm{Zr} \quad \mathrm{O}^{2-}, \mathrm{OH}^{-}, \mathrm{H}_{2} \mathrm{O}$

Glycine btc

Mn-MIL-100

aepa

appa

abpa

pyr

tri

btc

cdc

CAU-13

bdc

CAU-1

acac

phen

bipy

phen

bipy

acac

$\mathrm{RNPyS}_{4}$

acac

phen

$\mathrm{NP}_{3}$

Schmidt et al. (2012)

Schmidt and Stock (2011)

Schilling and Stock (2014)

Niekiel et al. (2013)

Ahnfeldt et al. (2011)

Ahnfeldt and Stock (2012)

Pienack et al. (2016a) and Pienack, Terraschke, and Bensch (2016b)

Terraschke et al. (2016)

Lindenberg et al. (2016)

Polzin, Eliani, and

Terraschke (2016)

Terraschke et al. (2016)

Lindenberg et al. (2016)

Polzin, Eliani, and

Terraschke (2016)

Pienack et al. (2016a) and Pienack, Terraschke, and Bensch (2016b)

Song et al. (2016)

Pienack et al. (2016a) and Pienack, Terraschke, and Bensch (2016b)

Terraschke et al. (2016)

Lindenberg et al. (2016)

Sarkar et al. (2014)

Albinati et al. (2002)

Jin (2016)

Bae et al. (2015)

Asanova et al. (2013)

Veligzhanin et al. (2013)

Yao et al. (2010)

dmp Elder et al. (1988)

tren

Kiebach et al. (2006)

Asanova et al. (2013) Jung and Czanderna (1994)

St. John et al. (2013)

Zadesenets et al. (2013)

gly

Pappas et al. (2009) 
$\mathrm{Zr} \quad \mathrm{OH}^{-}$

Glycolic acid

In situ resonant inelastic scattering (RIXS) spectroscopy

Fe $\quad \mathrm{Cl}^{-}, \mathrm{H}^{+}, \mathrm{H}_{2} \mathrm{O}$

In situ electrochemical scanning tunneling microscopy (EC-STM)

$\mathrm{Ru}$ 1-Butyl-3-methylimidazolium dicyanamide

In situ nuclear magnetic resonance (NMR) spectroscopy

Co, $\mathrm{Zn} \quad \mathrm{N}_{2} \mathrm{~S}$ (alkylthiolate)

2-Methyl-1-[methyl-(2-pyridin-2-ylethyl)amino]propane-2-thiolate

Al Trimesate
Hgly

Fitzgerald et al. (2009)

Bauer and Gastl (2010)

[BMIm][DCA] Mann et al. (2008)

PATH

btc
Chang et al. (2002)

Haouas et al. (2012)

Blanks indicate relevant information not supplied in the literature.

\section{In situ monitoring of optical properties}

\section{Luminescence}

\section{In situ luminescence analysis of coordination sensors (ILACS)}

The ILACS approach utilizes the sensitivity of lanthanide ions (including $\left.\mathrm{Eu}^{3+}, \mathrm{Eu}^{2+}, \mathrm{Ce}^{3+}, \mathrm{Tb}^{3+}\right)\left(\right.$ Binnemans, $^{2}$ 2015; Terraschke \& Wickleder, 2015; Terraschke et al. 2015a; 2015b) and transition metals (such as $\mathrm{Mn}^{2+}$ ) to the coordination environment to obtain information about processes occurring during the formation of solid materials. In this technique, these so-called coordination sensors are incorporated into the investigated materials and changes in the crystal structure are detected by recording in situ luminescence spectra under real reaction conditions, applying very fast charge-coupled device (CCD) detectors. In addition to its high sensitivity, which allows it to detect very low concentrations of impurities and characterize small crystallites or amorphous materials, this method is advantageous because it does not depend on synchrotron radiation, making it more practical to implement (Terraschke et al. 2016).

Two different setups for these in situ luminescence measurements have been reported, one stationary (Pienack et al., 2016a; Pienack, Terraschke \& Bensch, 2016b) and one mobile (Terraschke et al. 2016). The stationary setup consists of the combination of a fluorescence spectrometer (e.g. a Fluorolog ${ }^{\circledR}$-3) (HORIBA Jobin Yvon $\mathrm{GmbH}$, Unterhaching, Bavaria, Germany), equipped with an iHR-320-FA triple grating imaging spectrograph, a Syncerity CCD detector and a $450 \mathrm{~W}$ xenon lamp. Combining the xenon lamp and monochromators provided by the Fluorolog ${ }^{\circledR}-3$ spectrometer allows the application of flexible and high-intensity excitation energy, while the Syncerity CCD detector provides enhanced time and spectral resolution. As explained in detail in Section "Technical aspects of multiple combinations of in situ characterization methods", in this setup, the stationary spectrometer is connected to the reactor by a Y-shaped optical fiber which simultaneously transports excitation light to the reactor and light emitted by the reaction components back to the detector. The mobile ILACS setup utilizes a transportable luminescence spectrometer which is equipped with a CCD detector and optical fiber (e.g. from StellarNet Inc. or Ocean Optics Inc.), enabling easy transport of the necessary equipment, for example, to synchrotron facilities. Here, the excitation energy is provided by external UV light-emitting diodes (LEDs). The ability to transport this ILACS setup to the synchrotron facilities is advantageous to be able to carry out complementary characterization methods during, for example, in situ XRD analysis, which in contrast to in situ luminescence is not able to characterize ions in solution, very small crystallites or amorphous materials. In addition to the high flexibility of excitation energy and the mobility of the system, the mobile ILACS approach is also particularly advantageous because it utilizes a reactor which is external to the spectrometer. The external reactor system permits the reproduction of real reaction conditions, including stirring, heating, cooling, dosing, application of ultrasound or high pressure within the reaction vessel.

Complementary utilization of in situ XRD and ILACS has already been adopted by a number of research fields and has already provided interesting and important results. One example of this comes from investigations into the formation and decomposition of the $\left[\mathrm{Eu}(\mathrm{phen})_{2}\left(\mathrm{NO}_{3}\right)_{3}\right]$ complex (Figure 1). For this purpose, europium(III) nitrate was added to ethanol and placed inside the reactor, to which an ethanolic solution of 1,10-phenanthroline was added dropwise, being monitored simultaneously by in situ luminescence and IR spectroscopy as well as in situ XRD analysis at the Deutsches Elektronen-Synchrotron (DESY, Hamburg, Germany). The emission spectra of the initial solution of europium(III) nitrate in ethanol presented broad and low-intensity signals assigned to the ${ }^{5} \mathrm{D}_{0} \rightarrow{ }^{7} \mathrm{~F}_{\mathrm{J}}(\mathrm{J}=1-4) \mathrm{Eu}^{3+}$ electronic transitions caused by a quenching effect of the ethanol molecules within the $\mathrm{Eu}^{3+}$ solvation shell (Terraschke et al., 2015a; Yen, Yamamoto \& Shionoya, 2006). During the addition of the ligand solution, the emission spectra became gradually more intense and 
better resolved, indicating an exchange between the quenching solvent molecules and the phen ligands in the coordination sphere of Eu ${ }^{3+}$, which induces the so-called antenna effect (Streit et al. 2012).
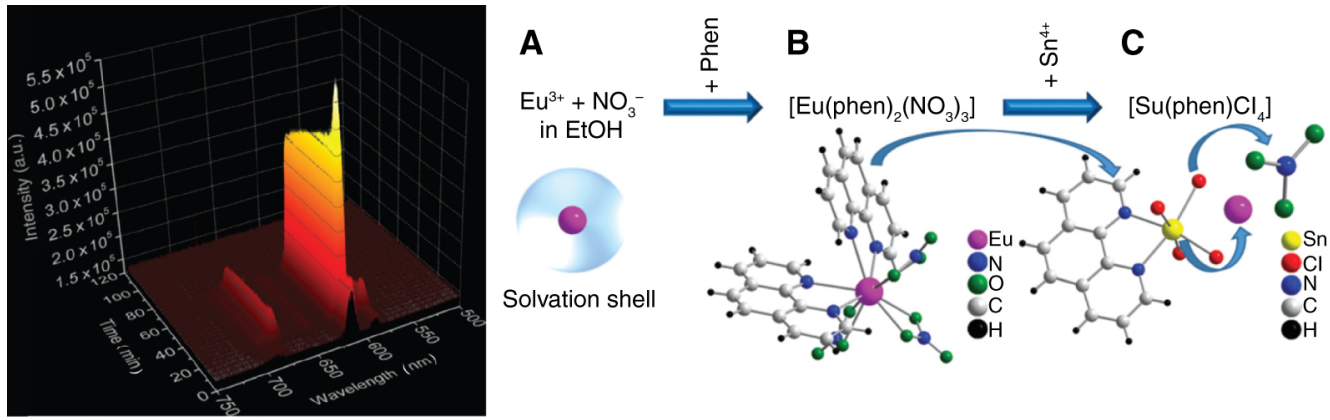

Figure 1: In situ luminescence measurements $\left(\lambda_{\mathrm{ex}}=395 \mathrm{~nm}\right)$ and schematic representation of metal-ligand exchange processes during the attachment of phen ligands to the $\mathrm{Eu}^{3+}$ ions $(\mathrm{A})$, formation of $\left[\mathrm{Eu}(\mathrm{phen})_{2}\left(\mathrm{NO}_{3}\right)_{3}\right](\mathrm{B})$ and the later detachment of the phen ligand molecules to form $\left[\mathrm{Sn}(\right.$ phen $\left.) \mathrm{Cl}_{4}\right](\mathrm{C})$. Reproduced with permission from Terraschke et al. (2016).

Upon the addition of $\mathrm{Sn}^{4+}$ ions, the luminescence signal decreased, indicating the decomposition of $\left.[\mathrm{Eu} \text { (phen })_{2}\left(\mathrm{NO}_{3}\right)_{3}\right]$ and the formation of $\left[\mathrm{Sn}(\mathrm{phen})\left(\mathrm{NO}_{3}\right)_{3}\right]$, which is non-luminescent at the examined excitation wavelength $(395 \mathrm{~nm})$. These results were confirmed by in situ XRD, IR, $\mathrm{pH}$ and conductivity analyses. Other studies which employed this setup afterward included the detection of the formation of a second polymorph of $\left.[\mathrm{Eu} \text { (phen) })_{2}\left(\mathrm{NO}_{3}\right)_{3}\right]$, a reaction intermediate of $\left[\mathrm{Eu}(\mathrm{phen})_{2}\left(\mathrm{NO}_{3}\right)_{3}\right]$ prior to its crystallization (Lindenberg et al. 2016), temporal monitoring of crystallization of the $\left[\operatorname{Ln}(\text { bipy })_{2}\left(\mathrm{NO}_{3}\right)_{3}\right]\left(\mathrm{Ln}=\mathrm{Eu}^{3+}, \mathrm{Tb}^{3+}\right)$ complex $($ Polzin, Eliani, and Terraschke 2016) and exploration of the crystallization process of inorganic compounds, including calcium phosphate derivatives (Terraschke et al. 2017).

\section{Time-resolved laser fluorescence spectroscopy (TRLFS)}

TRLFS represents another powerful in situ luminescence technique. This approach is able to detect variations in the first coordination sphere of fluorescent ions by measuring changes in the emission spectra, being mainly used to determine the number of fluorescence quenching entities by analyzing the fluorescence lifetime. This method is advantageous because it is non-invasive, allows direct analysis of solutions, solids and adsorbates (Tan, Fang \& Wang, 2010). The primary disadvantage of this method is the use of lasers as light source (e.g. NdYAG laser) (Moulin et al. 1999), which markedly restricts the variability of excitation wavelengths. This system is also not mobile and the measurements are mostly carried out in cuvettes, which hinders the reproduction of real reaction conditions and limits its combination with other in situ methods.

TRLFS is most often applied to probe the coordination chemistry of lanthanide and actinide ions with both organic (humic, fulvic and citric acid) and inorganic ligands (carbonates, sulfates and phosphates), particularly when being formed in aqueous solutions or at water/mineral interfaces (Buckau et al., 1992; Geipel, 2006; Geipel et al., 1996; Kato et al., 1994; Kim, Wimmer \& Klenze, 1991; Marang et al., 2009; Mathur, Cernochova \& Choppin, 2007; Panak et al., 1995; Tan, Fang \& Wang, 2010). Other interesting experiments have been carried out with this method for europium(III) complexes, including determining its hydration number in aqueous solution and its dissociation kinetics during the formation of $[\mathrm{Eu}(\operatorname{dotp})]^{5-}$ (Piskula et al., 2007; Táborsky et al., 2007). In the latter of these, the $\mathrm{Eu}(\mathrm{III})$ complex was reacted with $\mathrm{H}_{8} \operatorname{dotp}\left(\mathrm{H}_{8} \mathrm{dotp}=1,4,7,10-\right.$ tetraazacyclododecane-1,4,7,10-tetrakis(methylphosphonic acid)) and TRLFS was employed to estimate the time dependence of the average number of water molecules in the inner sphere of $[\mathrm{Eu}(\operatorname{dotp})]^{5-}$ during an acid-assisted complex dissociation by $\mathrm{HCl}$ and $\mathrm{HClO}_{4}$. The experimental luminescence decay was summarized as

$$
I_{t}=I_{0} \cdot e^{-1 / \tau}
$$

with the linearized logarithmic form

$$
\ln \left(I_{t}\right)=\ln \left(I_{0}\right)-\frac{1}{\tau} \cdot t
$$

with $I_{t}$ and $I_{0}$ representing the measured and the initial luminescence intensity, respectively. Here, $t$ is the time and $\tau$ the lifetime of the luminescence decay. The hydration number $q$ of the europium(III)-containing species was determined to be 


$$
q=1.05 \cdot \tau^{-1}-0.7
$$

This equation was previously empirically determined based on the experiments of, for example, Barthelemy and Choppin (1989), in which it was shown that the luminescence lifetime of $\mathrm{Eu}^{3+}$ upon complexation in solution is nearly independent of the type of ligand but strongly correlates with the number of water molecules in the primary coordination sphere of trivalent europium ions. In Section "UV/Vis absorption spectroscopy", the formation of the $[\mathrm{Eu}(\operatorname{dotp})]^{5-}$ complex is further discussed in relation to its employed in situ absorption spectroscopy (Piskula et al. 2007).

\section{UV/Vis absorption spectroscopy}

Use of UV/Vis absorption spectroscopy to examine chemical reactions has been reported in the literature as early as the 1940s, when prominent scientists such as Lewis and co-workers employed it to study the formation mechanism of free radicals, called at the time "odd molecules," by examining the interaction between light and chromophores with large molecular substituents (Coffey, 2008). Free radicals are rather unstable, losing or gaining electrons for the formation of positively or negatively charged ions, being combined as intermediates within microseconds to other molecules. Because of their high instability, they cannot be analyzed under normal experimental conditions. For this reason, a method to trap these highly reactive species long enough to detect them was developed. They accomplished this by cooling the solution of interest until it formed a glass-like consistency, creating a "rigid media." Upon light radiation, the free radicals and ions were formed, but could not move to recombine in bimolecular reactions. The studied species were deeply colored and could be evaluated spectroscopically (Coffey, 2008).

In more recent years, in situ UV/Vis absorption spectroscopy has been utilized to investigate the decomposition reaction of the $[\mathrm{Eu}(\mathrm{dopt})]^{5-}$ complex, previously mentioned in regard to TRLFS measurements (Piskula et al. 2007). Piskula et al. were investigating the possible application of macrocyclic ligands of $\mathrm{H}_{8}$ dotp for binding metal radioisotopes, allowing them to be used as carriers in nuclear medicine. For an efficient sequestration, the resulting complex must present kinetic inertness and high thermodynamic stability. These characteristics were therefore investigated with the aid of dissociation kinetics by means of UV/Vis absorption spectroscopy. An acid-assisted decomposition reaction with this complex was, therefore, monitored and changes in the intensity of the charge transfer (CT) band of the $[\mathrm{Eu}(\mathrm{dopt})]^{5-}$ complex at $275 \mathrm{~nm}$ were recorded (Figure 2). Data analysis revealed a temperature-dependent monotonical decrease of the band as the reaction progressed, slow at room temperature and accelerated upon a temperature increase. This decay is applied for the determination of the pseudo-first-order rate constant ${ }^{\mathrm{Ln}} k_{d, \text { obs }}$ of the dissociation reaction for the Ln complex with the L ligand, in relation to the time dependence of the complex concentration [complex] and to the total complex concentration $[\text { complex }]_{\text {tot }}$, defined as

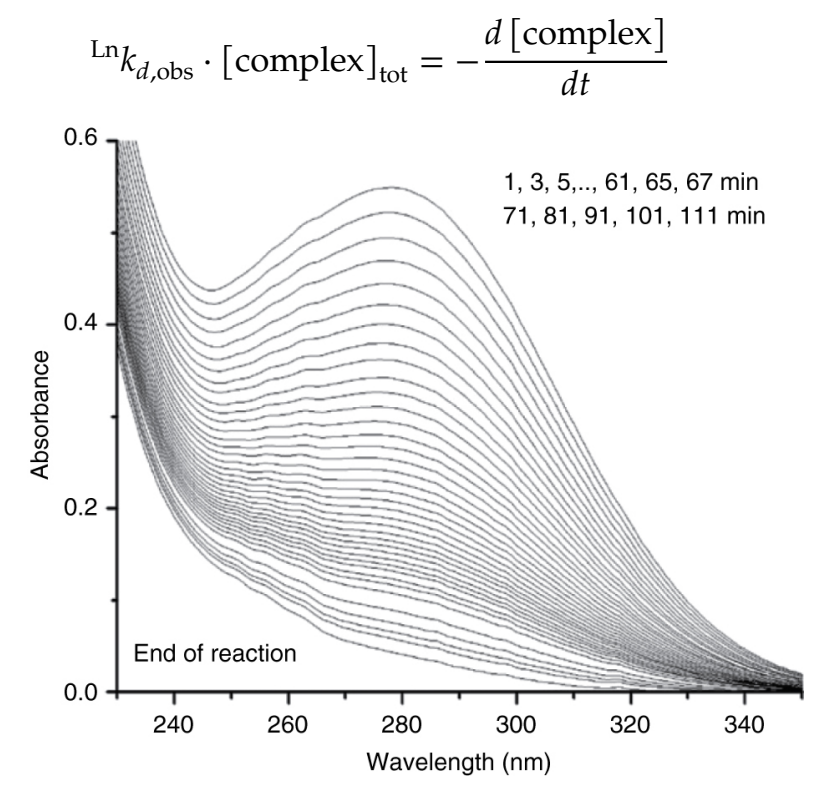

Figure 2: Example of time-resolved absorption spectra during acid-assisted dissociation of the $\mathrm{Eu}^{3+}$ complex with $\mathrm{H}_{8} \mathrm{dotp}$. Reproduced with permission from Piskula et al. (2007). Copyright 2007 Elsevier. 
and a dissociation reaction postulated as

$$
\mathrm{LnL}+n \mathrm{H}^{+} \leftrightarrows \mathrm{Ln}\left(\mathrm{H}_{n} \mathrm{~L}\right) \stackrel{\text { Ln } k_{d, \mathrm{obs}}}{\longrightarrow} \mathrm{Ln}^{3+}+\mathrm{H}_{n} \mathrm{~L}
$$

An example of the utilization of in situ UV/Vis absorption spectroscopy in combination with XRD is the analysis of the nucleation mechanism and molecular morphology of platinum nanocrystals, which was carried out at U7C station in NSRL (National Synchrotron Radiation Laboratory, P.R. China) and 1W1B station in BSRF (Beijing Synchrotron Radiation Facility, P.R. China) (Yao et al. 2012). For this synthesis, $\mathrm{K}_{2} \mathrm{PtCl}_{4}$ was used as a precursor, while either citric acid or ethylene glycol was used as a strong or weak reducing agent, respectively. Poly(vinylpyrrolidone) (PVP) was added in both experiments as a stabilizer. UV/Vis absorption spectra were collected perpendicular to the incident $X$-ray beam every $70 \mathrm{~s}$. The absorption spectra were not recorded directly in the reactor but in an external quartz cuvette, connected to the reactor by microtubes, which transported the reactor content to the measurement cuvette by means of a peristaltic pump. Figure 3 shows the in situ UV/Vis absorption spectra recorded during the formation of $\mathrm{Pt}$ nanocrystals by the reduction of the precursor by ethylene glycol and citric acid. Initially, the $\mathrm{PtCl}_{4}{ }^{2-}$ precursor showed a maximum at $220 \mathrm{~nm}$, which was determined to stem from the metal-to-ligand (Pt-Cl) CT (Yao et al. 2012). Differences in the range of 245 and $255 \mathrm{~nm}$ indicate distinct reduction routes for each of the reducing agents (Yao et al. 2012). When ethylene glycol is added, the initial peak at $245 \mathrm{~nm}$ shifts to $255 \mathrm{~nm}$ within the first $100 \mathrm{~min}$. Afterward, this intermediate absorbance band decreases and disappears. When citric acid is added, a monotonic transition from precursor to nanocrystal is observed. Because the peaks at 245-255 nm cannot be assigned to $\mathrm{PtCl}_{4}{ }^{-}$or $\mathrm{Pt}_{n}{ }^{0}$ clusters (featureless in this spectral region), this band indicates the formation of an intermediate Pt complex. The in situ XAS spectroscopy data corroborate these observations, also indicating one nucleation mechanism for weak reductants and one for strong reductants. The introduction of a weak reductant appears to induce the formation of one-dimensional $\mathrm{Pt}_{n} \mathrm{Cl}_{x}$ complexes, formed by the polymerization of $\mathrm{Cl}_{3} \mathrm{Pt}_{-} \mathrm{PtCl}_{3}$ linear dimers, resulting in the formation of nanowires. The introduction of a strong reductant appears to result in the formation of spherical $\mathrm{Pt}_{n}{ }^{0} \mathrm{Clusters}$ which, when further reacted, ultimately form nanospheres (Yao et al. 2012).
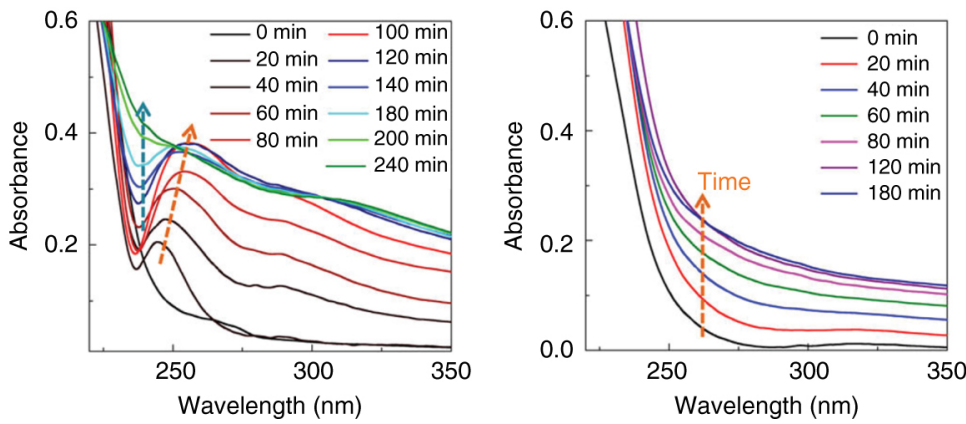

Figure 3: In situ UV/Vis absorption spectra recorded during reduction of $\mathrm{K}_{2} \mathrm{PtCl}_{4}$ precursor with ethylene glycol (left) and citric acid (right) for the formation of Pt nanocrystals (Yao et al. 2012). Reprinted with permission from Yao et al. (2012). Copyright 2012 American Chemical Society.

\section{In situ light transmission}

Another interesting approach for in situ monitoring of the formation of solid materials is the measurement of the transmission of light through the reactor solution during the reaction. For this purpose, a light source is placed outside the reactor and an optical fiber connected to a CCD detector is submersed in the reactor content. During the formation of the product, the turbidity of the mother solution increases, decreasing the intensity of detected light. During the partial dissolution of the product during phase transformations, the turbidity decreases and the intensity of the light source consequently increases. The advantage of this approach, compared with in situ luminescence measurements, is that it does not require reactants or product to possess luminescent properties and allows the use of different wavelengths of light, which increases flexibility in the light source and its applicability.

Recently, this method was applied for studying the formation of $\mathrm{Al}(\mathrm{acac})_{3}$, often employed as a precursor for the production of $\mathrm{Al}_{2} \mathrm{O}_{3}$ NPs and thin films (Hafshejani et al., 2016; Kim et al., 1993). By complementing this method with in situ XRD at the PETRA III beamlines P07B and P09 (DESY), luminescence, IR, pH and redox potential, it was possible to determine the induction time depending on the synthesis parameters and to investigate the transition between the $\mathrm{Al}(\mathrm{acac})_{3} \alpha$ - and $\gamma$-polymorphs. Specifically, the transmittance measurements 
during the addition of $\mathrm{NH}_{3}$ solutions to a solution of $\mathrm{Al}\left(\mathrm{NO}_{3}\right)_{3} \bullet 9 \mathrm{H}_{2} \mathrm{O}$ and acetylacetone helped in this case to determine the influence of the $\mathrm{NH}_{3}$ concentration or rather the $\mathrm{pH}$ value on the crystallization time of the $\mathrm{Al}(\mathrm{acac})_{3}$ complex. Figure 4 shows, for instance, the time dependence of the intensity of the light source through during the $\mathrm{Al}$ (acac) $)_{3}$ crystallization applying a $25 \% \mathrm{NH}_{3}$ solution. Due to the initially high transparency of the $\mathrm{Al}\left(\mathrm{NO}_{3}\right)_{3} \bullet 9 \mathrm{H}_{2} \mathrm{O}$ and acetylacetone solutions before crystallization, the recorded intensity of the light source reaches its highest values. During the addition of the $\mathrm{NH}_{3}$ solution in the first 18 min of the reaction, the light transmission starts abruptly to decrease after $t \approx 2 \mathrm{~min}$, indicating the increase of the turbidity caused by the formation of the product, which was confirmed by in situ powder diffractograms recorded simultaneously at the P09 beamline. Afterward, the light transmission starts to increase again, indicating a decrease in the turbidity of the solution and a possible partial dissolution of the product. Decreasing the $\mathrm{NH}_{3}$ concentration to $12.5 \%$, the begin of the crystallization was shifted to $t \approx 4 \mathrm{~min}$. Interestingly, decreasing the $\mathrm{NH}_{3}$ concentration to $2.5 \%$, the decrease of the light transmission indicates the formation of the solid material, even though the crystallinity of the product was not sufficiently high to be detected by in situ XRD.
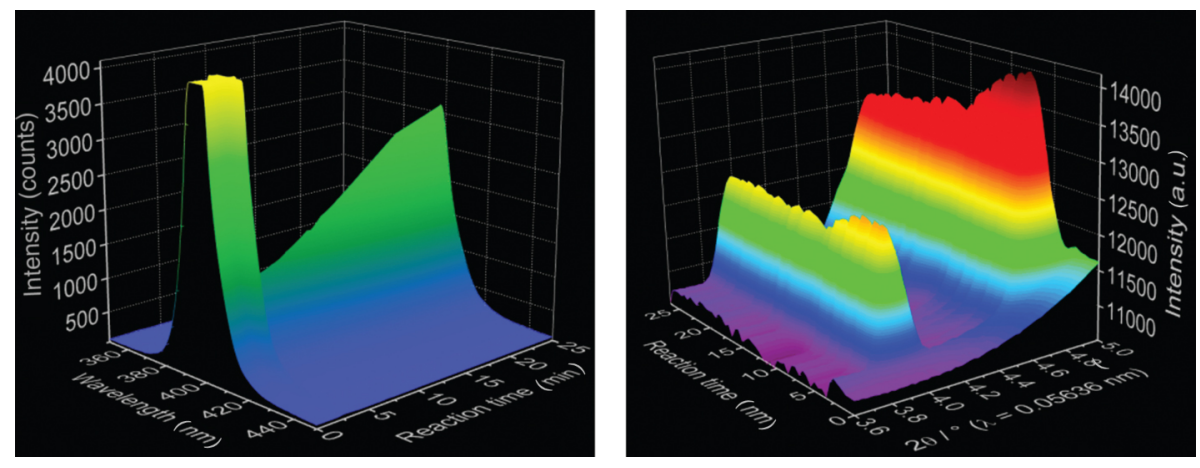

Figure 4: Time dependence of the detected intensity of the light source (left) and XRD reflections measured at the P09 DESY beamline (right), recorded during synthesis of $\mathrm{Al}(\mathrm{acac})_{3}$ applying a $25 \% \mathrm{NH}_{3}$ solution. Reproduced with permission from Pienack et al. (2016a) and Pienack, Terraschke, and Bensch (2016b).

In summary, in situ light transmission measurement is a powerful complementary tool to in situ XRD techniques, allowing acquisition of information about the solution turbidity during reactions. Generally speaking, in situ XRD patterns can be quantitatively analyzed to determine whether the mechanism of phase transitions is a solid-solid transformation, amorphization or dissolution of reactants and intermediates (Engelke et al. 2003). Light transmission measurements can be used to help clarify if the disappearance of Bragg reflections in the in situ XRD is caused by amorphization of the solid material or dissolution of the prior phase, depending on whether the intensity of light transmission remains constant or exhibits a transient decrease. This principle could not be demonstrated for the $\mathrm{Al}(\mathrm{acac})_{3}$ example described above, because, in contrast to the measurements carried out at the P07B DESY beamline within this same study, the single reflections assigned to the respective $\alpha$ - and $\gamma$-polymorphs measured at the P09 beamline simultaneously to the in situ light transmission measurements strongly overlap, whose resolution was sufficient for a qualitative but not a quantitative analysis. This principle can be applied, however, for instance for compounds, whose reflections of the intermediate and final products are more distant from each other and present less overlap.

\section{In situ XRD analysis}

In situ XRD is a vital technique for acquiring information about changes in the crystal structure during chemical reactions. However, laboratory X-ray sources present a limited intensity and their detectors offer low time resolution, impairing the characterization of fast reaction processes, such as nucleation and formation of shortlived intermediates. For efficient in situ XRD measurements in solution, high-energy and high-flux X-rays are necessary in order to penetrate the reactor walls and the solvent bulk volume. These high-energy X-rays, either white (energy dispersive) or monochromatic, are usually available in synchrotron facilities such as the DESY, the Source Optimisée de Lumière d'Energie Intermédiaire du-LURE (SOLEIL) in France, the Diamond Light Source in the United Kingdom, and MAX IV in Sweden, to name only a few.

A common challenge for the application of synchrotron radiation for monitoring chemical reactions is the construction of reactors which mimic real laboratory conditions, allowing for appropriate physical manipulations, such as stirring, dosing, cooling, heating and, sometimes, under pressure. Stirring is especially important in order to avoid settling of solid material during the measurements, which can introduce inappropriate oscillations in the intensity of XRD reflections. Maintaining adequate stirring capacity is made technically difficult 
by the fact that high concentrations of solutes are required to reduce the signal-to-noise ratio during in situ XRD measurements. This is particularly problematic for glass tube reactors with small diameters, in which an inefficient stirring can cause inhomogeneous crystallization of the product on the solution surface or near the reactor walls. Thus, the products might be formed outside the region where the beam passes through the reactor, hindering their detection. Insufficient stirring may also allow for crystallization of solid material on the solution's surface when additional reactants are added during the reaction, preventing diffusion of the added reactant through the reaction solution at proper concentrations and altering the nature of the synthesis milieu. For further technical considerations concerning the construction of these types of reactors, the review by Walton and $\mathrm{O}^{\prime}$ Hare (2000) is strongly recommended.

An example of synthesis conditions challenging for synchrotron facilities is solvothermal syntheses, carried out under autogenous pressure and heating solvents above their boiling point, facilitating the dissolution of reactants with poor solubility under normal atmospheric conditions. The products of this complex reaction system, which is often utilized for the production of MOFs, polyoxo- and chalcogenide metallates (explored more fully below), are exceptionally sensitive to numerous reaction parameters, including reaction time, temperature, autogenous pressure, reactant concentrations, type of solvents, $\mathrm{pH}$ and viscosity. Under laboratory conditions, reactors are sealed in an oven for the duration of the synthesis (a time range that frequently varies between days and weeks), preventing the collection of data concerning the influence of single isolated parameters on the reaction, especially because the alteration of one parameter causes a strong change of many others (Seidlhofer et al. 2012). Stirring the reactor content (dynamic solvothermal synthesis) can reduce the reaction time to few hours, which facilitates analysis of the entire synthesis reaction and the influence of the complex combination of reaction parameters within the available beamtime in synchrotron facilities.

In Sections "Complexes and CP", "Porous materials", and "Polyoxo- and chalcogenide metallates", selected examples of synchrotron-based in situ XRD applications are discussed. These examples focus on the qualitative analysis of metal-ligand exchange processes involved in the formation, phase transformation and dissolution of solid materials as well as monitoring and controlling the influence of reaction parameters on these processes. Quantitative kinetic analysis of the in situ XRD data via the methods developed by Gualtieri (2001), Hancock and Sharp (1972), and Avrami $(1939,1940,1941)$ is not discussed in detail here.

\section{Complexes and CP}

The solid-state reaction between $\mathrm{FeSO}_{4} \bullet 7 \mathrm{H}_{2} \mathrm{O}$ and 1,10-phenanthroline has been monitored by Lei et al. (2002) by time-resolved energy-dispersive XRD (EDXRD) analysis. For this purpose, the white beam at the Station 16.4 of the synchrotron radiation source at the Daresbury Laboratory, United Kingdom, was applied. The reaction was carried out in Pyrex tubes with 1-mm-thick walls, equipped with a heating apparatus. Spectra were recorded every $30 \mathrm{~s}$. It could be determined that upon reaching $70^{\circ} \mathrm{C}$, a rapid ligand substitution reaction occurs, indicated by a color change from pale green to red, which is completed within approximately $10 \mathrm{~min}$. The final product was identified as $\mathrm{Fe}(\mathrm{phen})\left(\mathrm{H}_{2} \mathrm{O}\right) \mathrm{SO}_{4}$ by indexing the in situ collected Bragg reflections. Before the formation of the final product, at approximately $4.5 \mathrm{~min}$, reflections of a transient intermediate phase appear, which were indexed and identified as $\mathrm{Fe}$ (phen) ${ }_{3} \mathrm{SO}_{4} \bullet 5 \mathrm{H}_{2} \mathrm{O}$. In order to confirm that $\mathrm{Fe}$ (phen) ${ }_{3} \mathrm{SO}_{4} \bullet 5 \mathrm{H}_{2} \mathrm{O}$ is the precursor to $\mathrm{Fe}$ (phen) $\left(\mathrm{H}_{2} \mathrm{O}\right) \mathrm{SO}_{4}$, an independent experiment was conducted in which $\mathrm{Fe}(\mathrm{phen})_{3} \mathrm{SO}_{4} \bullet 5 \mathrm{H}_{2} \mathrm{O}$ was separately heated with $\mathrm{FeSO}_{4} \bullet 7 \mathrm{H}_{2} \mathrm{O}$ to $70^{\circ} \mathrm{C}$. Indeed, $\mathrm{Fe}(\mathrm{phen})\left(\mathrm{H}_{2} \mathrm{O}\right) \mathrm{SO}_{4}$ was produced as a final product, confirming this hypothesis. Interestingly, this mechanism differs from the pathway in aqueous solution, in which $\left[\mathrm{Fe}(\text { phen })_{3}\right]\left[\mathrm{SO}_{4}\right]$ is formed instead (Lei et al. 2002).

Another application of synchrotron X-rays for monitoring chemical reactions is the analysis of the thermal decomposition of the $\left[\mathrm{Rh}\left(\mathrm{NH}_{3}\right)_{5} \mathrm{Cl}\right]\left[\mathrm{PtCl}_{4}\right]$ complex to form $\mathrm{Pt}_{0.5} \mathrm{Rh}_{0.5}$ nanosized powder under different atmospheres (Shubin, Korenev, and Sharafutdinov 2006). These experiments were performed at the $5 \mathrm{~b}$ beamline of the VEPP-3 storage ring in the G. I. Budker Institute of Nuclear Physics of the Siberian Branch of the Russian Academy of Sciences. The applied synchrotron radiation wavelength was $\lambda=1.504 \AA$ and the diffractograms were recorded every $10 \mathrm{~min}$ with an exposure time of $1 \mathrm{~min}$. The samples were prepared by pressing the $\left[\mathrm{Rh}\left(\mathrm{NH}_{3}\right)_{5} \mathrm{Cl}\right]\left[\mathrm{PtCl}_{4}\right]$ complex into the cavity of a stainless steel cell. The in situ XRD data demonstrated that, in the vacuum, the complex structure remains unchanged up to $235^{\circ} \mathrm{C}$. At $250^{\circ} \mathrm{C}$, the XRD patterns show broad and low-intensity reflections of $\mathrm{Pt}$, accompanied by an increase of the background reflections at diffraction angles coinciding with the $\mathrm{Pt}_{0.5} \mathrm{Rh}_{0.5}$ solid solution. At $280^{\circ} \mathrm{C}$, the anionic part of the complex is completely decomposed and platinum is reduced, characterized by a strong increase in the Pt reflection. Increasing the temperature up to $500^{\circ} \mathrm{C}$ results in the destruction of the cationic coordination sphere and elimination of Rh, which reacts with $\mathrm{Pt}$ to form the solid solution. Increasing intensity of reflections of the solid solution at this point coincides with the decrease of Pt reflections. The process is completed when the reaction reaches $550^{\circ} \mathrm{C}$. Under 
hydrogen atmosphere, reduction of $\left[\mathrm{Rh}\left(\mathrm{NH}_{3}\right)_{5} \mathrm{Cl}\right]\left[\mathrm{PtCl}_{4}\right]$ is initiated at lower temperatures (Shubin, Korenev, and Sharafutdinov 2006).

An example of in situ monitoring of the crystallization of $\mathrm{CP}$ is the ionothermal formation of an indium imidazolate (im) framework $\mathrm{In}(\mathrm{im})_{3}$ with formula $\mathrm{C}_{9} \mathrm{H}_{9} \mathrm{InN}_{6}$, which was examined by 2-min interval in situ EDXRD measurements at the DESY beamline F3 at DORIS III (Schweinefuß et al. 2014). Analysis of the data revealed that the octahedrally coordinated $\mathrm{In}^{3+}$ ions are interconnected by imidazolate ligands, forming a three-dimensional framework with a distorted filled- $\mathrm{ReO}_{3}\left(\mathrm{ABX}_{3}\right.$ perovskite) structure. This was determined by monitoring each step of the reaction, beginning with the solution of imidazole (Him) and $\mathrm{In}\left(\mathrm{NO}_{3}\right)_{3} \bullet 3 \mathrm{H}_{2} \mathrm{O}$ in 1-ethyl-3-methylimidazolium bis-[trifluoromethylsulfonyl]imide $\left(\mathrm{C}_{8} \mathrm{H}_{11} \mathrm{~F}_{6} \mathrm{~N}_{3} \mathrm{O}_{4} \mathrm{~S}_{2}\right.$, EMim-NTf 2 ) in a tightly sealed $7 \mathrm{ml}$ borosilicate glass tube. The tube reactors were then heated to $160-180^{\circ} \mathrm{C}$ with magnetic stirring for approximately $40-120$ min using preheated circulating oil. For reactions which were maintained at $160^{\circ} \mathrm{C}$, the induction period was approximately $50 \mathrm{~min}$, at which point the reflections of $\mathrm{C}_{9} \mathrm{H}_{9} \operatorname{InN} \mathrm{N}_{6}\left(\operatorname{In}(\mathrm{im})_{3}\right)$ begin to appear, growing intensively until the end of the crystallization process at ca. $90 \mathrm{~min}$, obtaining a pure phase product. As expected, higher temperatures led to shorter induction periods and the end of the crystallization process was reached more quickly, as was shown by the plateau of the intensity of the Bragg reflections after approximately $30 \mathrm{~min}$. The in situ EDXRD data were utilized for accurate calculation of the rate constants and activation energy for nucleation and crystal growth (Schweinefuß et al. 2014).

\section{Porous materials}

Porous materials are especially important for applications such as gas storage, catalysis, drug delivery or molecular sensors, in which guest molecules can be loaded within the structure voids (Kitagawa, Kitaura \& Noro, 2004). Among the most versatile of these materials are MOFs (Rowsell \& Yaghi, 2004), which comprise combinations of inorganic and organic building units usually consisting of individual metal ions or ion clusters interconnected by organic ligands to create a porous three-dimensional network (Lammert et al., 2016; Streit et al., 2012). Altering the metal moieties and size of the organic ligands provides remarkable flexibility to adjust pore size and network geometry to meet specific technological requirements. Interestingly, most MOFs possess intrinsic luminescent properties (Lammert et al., 2016; Lestari et al. 2014a; 2014b; 2014c) due to the extended conjugated $\pi$ system within the organic ligands, enhancing their potential application for sensing guest molecules or ions as well as for the use in the production of organic LEDs. Because properties such as pore size and luminescence are strongly governed by the atomic arrangement of the material, efficient generation of desired properties strongly depends on adequate knowledge and control over the formation of the respective crystal structure, which is drastically improved by data obtained by in situ characterization techniques.

The new SynRAC (Synchrotron-based Reaction cell for the Analysis of Chemical reactions) system (Figure 5) consists of an easy to use, versatile reactor for studying the formation of porous materials as well as their interactions with guest molecules and allows performing in situ analysis techniques such as in situ XRD or XAS during solvothermal synthesis (Heidenreich et al. 2017). This reactor system provides efficient temperature control and allows for the addition of reactants via an automatic pump system, enabling the study of the reaction dynamics in response to altered temperature or reactant composition. The experimental setup is designed to accommodate two sizes of borosilicate glass reaction vessels with volumes of 5 and $11 \mathrm{ml}$. These disposable reaction vessels provide significant advantages over reusable reactors. Not only are they more cost-effective, but they also eliminate potential cross-contamination between experiments and the need to realign the cell after each reaction (Heidenreich et al. 2017). 


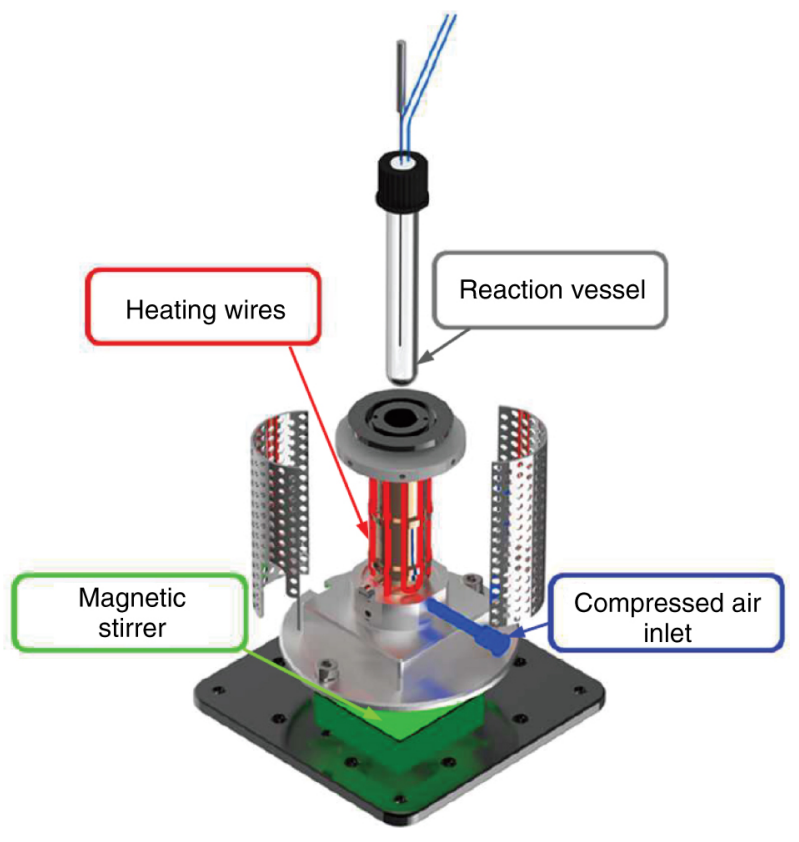

Figure 5: Schematic representation of the new SynRAC developed at the University of Kiel in cooperation with the DESY synchrotron facility. Reproduced from Reinsch et al. (2017) with permission from The Royal Society of Chemistry.

The SynRAC reactor presents integrated stirring and heating systems (up to $200^{\circ} \mathrm{C}$ ), being built on a ground plate designed to quickly fit onto different beamlines (Heidenreich et al. 2017). The heating setup is composed of a mantle containing heating wires, cooled by pressured air. In order to correct for the effect of beam intensity fluctuation, which often originates in the monochromators or storage ring, the SynRAC system is additionally equipped with aluminum windows, which allows the use of Al reflections as an external standard to normalize the in situ XRD patterns to the fluctuation of beam intensity. During the reaction, additional intensity fluctuation on the in situ XRD patterns can be explained by the change of the distribution of particles within the beam pathway in the reaction vessel. The application of this new system is demonstrated for analyzing the crystallization kinetics of materials such as the Ce-UiO-66 $\left[\mathrm{Ce}_{6}(\mathrm{OH})_{4}(\mathrm{O})_{4}(\mathrm{BDC})_{6}\right]$ $\mathrm{MOF}$, detecting a short-lived intermediate during the synthesis of the [Bi(HIDC)(IDC)] (IDC $=4,5$ imidazoledicarboxylate) Heidenreich et al. (2017), besides studying the breathing effect of the CAU-13 $[\mathrm{Al}(\mathrm{OH})(\mathrm{CDC})]$ (CDC ${ }^{2-}=$ trans-1,4-cyclohexanedicarboxylate) MOF (Reinsch et al., 2017).

An interesting example of the application of in situ synchrotron powder XRD was the surveillance of the formation of lithium tartrate MOFs with formula $\mathrm{Li}_{2-x} \mathrm{H}_{x}-\left(\mathrm{C}_{6} \mathrm{H}_{4} \mathrm{O}_{6}\right)\left(\mathrm{H}_{2} \mathrm{O}\right)_{y}$ via solvothermal synthesis at beamline I12 at the Diamond Light Source in the United Kingdom (Yeung et al. 2016). The reaction was carried out in a large volume reactor composed of borosilicate glass tubes with polytetrafluoroethylene-lined screwcaps under conditions comparable with those in a laboratory. Thermocouples were passed through the screwcaps to monitor the temperature of the reaction as it was heated to $124^{\circ} \mathrm{C}$ using an oil bath. The reaction was continuously stirred via a magnetic stirring system. Monochromatic X-ray $(\lambda=0.2326 \AA)$ diffraction data were recorded in situ and analyzed to calculate the kinetic rate constants and activation energy (Yeung et al. 2016). The in situ XRD results identified the crystallization and dissolution of three competing phases, with the thermodynamically stable product $\mathrm{Li}_{2}$ (meso- $\left.\mathrm{C}_{6} \mathrm{H}_{4} \mathrm{O}_{6}\right)$ crystallizing after the consecutive formation of two other phases. The first intermediate consisted of the hydrate analogous $\mathrm{Li}_{2}$ (meso- $\left.\mathrm{C}_{6} \mathrm{H}_{4} \mathrm{O}_{6}\right)\left(\mathrm{H}_{2} \mathrm{O}\right)_{0.5}$ and the second intermediate was found to be the metastable anhydrous polymorph $\mathrm{Li}_{2}\left(\right.$ meso- $\mathrm{C}_{6} \mathrm{H}_{4} \mathrm{O}_{6}$ ) of the product (Figure 6). In addition to identifying these intermediary phases, the in situ XRD data also indicated that the conversion processes between the intermediate phases and the final product occur by dissolution and recrystallization, rather than through solid-solid transformation.

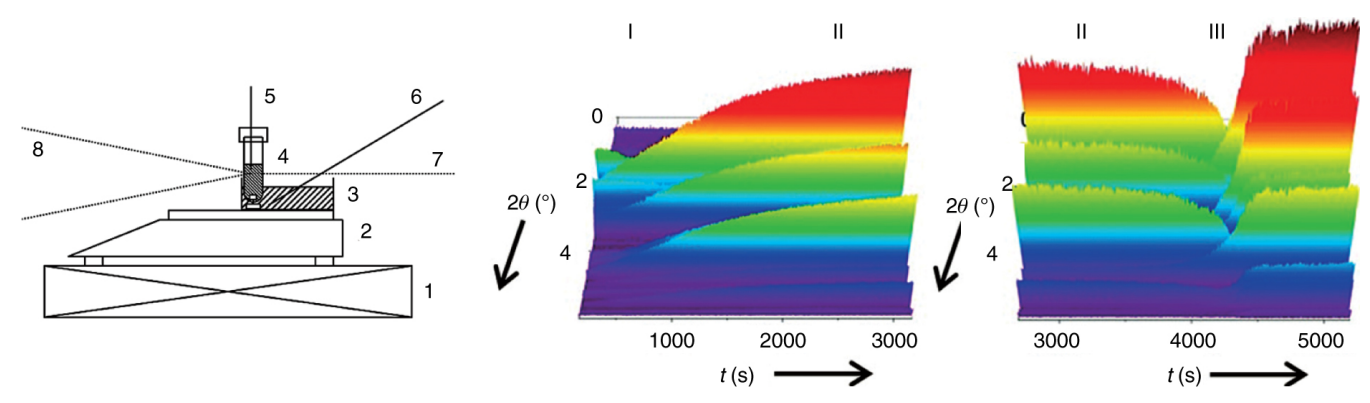


Figure 6: Reactor setup including (1) an adjustable stage, (2) stirrer and hotplate, (3) an oil bath containing a magnetic stirrer, (4) reactor with screwcap and magnetic stirrer, (5 and 6) thermocoupling, (7) incoming and (8) diffracted X-ray beam (left). Time-dependent in situ XRD patterns showing the formation of the $\mathrm{Li}_{2}\left(\right.$ meso- $\left.\mathrm{C}_{6} \mathrm{H}_{4} \mathrm{O}_{6}\right)\left(\mathrm{H}_{2} \mathrm{O}\right)_{0.5}$ during the reaction period I, followed by the crystallization of the anhydrous $\mathrm{Li}_{2}\left(\right.$ meso- $\left.\mathrm{C}_{6} \mathrm{H}_{4} \mathrm{O}_{6}\right)$ metastable intermediate during reaction period II and the formation of the thermodynamically stable polymorph final product during reaction phase III (right) (Yeung et al. 2016). Copyright Wiley-VCH Verlag GmbH \& Co. KGaA. Reproduced with permission.

Information about the processes occurring during the decomposition of metal-ligand complexes can be useful for better characterization of complexes and improvement of product stability. One illuminating example of this is the analysis by in situ XRD of the temperature dependence of the $\mathrm{Nd}(\mathrm{btc})\left(\mathrm{H}_{2} \mathrm{O}\right) \bullet \mathrm{DMF}$ MOF crystal structure carried out by Gustafsson et al. in 2008. This work utilized monochromatic synchrotron radiation $(\lambda=1.250 \AA)$ at the beamline I711 at the MAX Lab in Sweden. Briefly, the team discovered that in the temperature range of $150-200^{\circ} \mathrm{C}$, a shift of reflections to higher angles could be observed, which they attributed to changes in the framework to lower symmetry caused by the release of solvent molecules from the MOF pores (Gustafsson et al. 2008). At $300^{\circ} \mathrm{C}$ all solvent molecules are expelled and the framework forms an intermediate with tetragonal symmetry. This symmetry is lost at $400^{\circ} \mathrm{C}$, at which temperature the btc ligand begins to degrade, and the complexes take on an amorphous state (Gustafsson et al. 2008).

Francis et al. (1996), working in the UK Synchrotron Radiation Source at Daresbury Laboratory, reported in situ XRD measurements during the hydrothermal synthesis of a microporous tin sulfide (tma)-SnS-1 (tma = tetramethylammonium) with the empirical formula $\left(\mathrm{NMe}_{4}\right)_{2} \mathrm{Sn}_{3} \mathrm{~S}_{7} \bullet x \mathrm{H}_{2} \mathrm{O}$. For this purpose, elemental tin and sulfur were added to a tetramethylammonium hydroxide solution in a specially designed hydrothermal cell (Figure 7) and heated to one of three temperatures $\left(120^{\circ} \mathrm{C}, 150^{\circ} \mathrm{C}\right.$ or $\left.175^{\circ} \mathrm{C}\right)$. The cell was composed of a stainless steel tube with $0.7 \mathrm{~mm}$ walls, which allowed for the passage of the synchrotron X-ray beam. The stainless steel tube was lined with Teflon to reduce the contact of the reaction content with the cell walls, and the cell was connected to a pressure transducer and a pressure relief valve to allow regulation of reaction pressure. Heating was achieved by circulation of hot oil through gantries cut through a mantling solid copper block. Examining the obtained data, similar results were found for $120^{\circ} \mathrm{C}$ and $150^{\circ} \mathrm{C}$, with an induction time of approximately $20 \mathrm{~min}$ before the appearance of the first peak, which grew rapidly for $120 \mathrm{~min}$ followed by a more gradual increase for additional 3 days. Complementary laboratory XRD measurements identified the presence of one monoclinic and one orthorhombic polymorph as products of the syntheses at these two temperatures. At $175^{\circ} \mathrm{C}$, the induction time was reduced to $10 \mathrm{~min}$ with the major formation of the orthorhombic polymorph presenting only trace impurities of the monoclinic phase. Complementary experiments have also been carried out to analyze the effect of $\mathrm{pH}$ and the reactant source on the crystal growth of this compound (Francis et al. 1996).

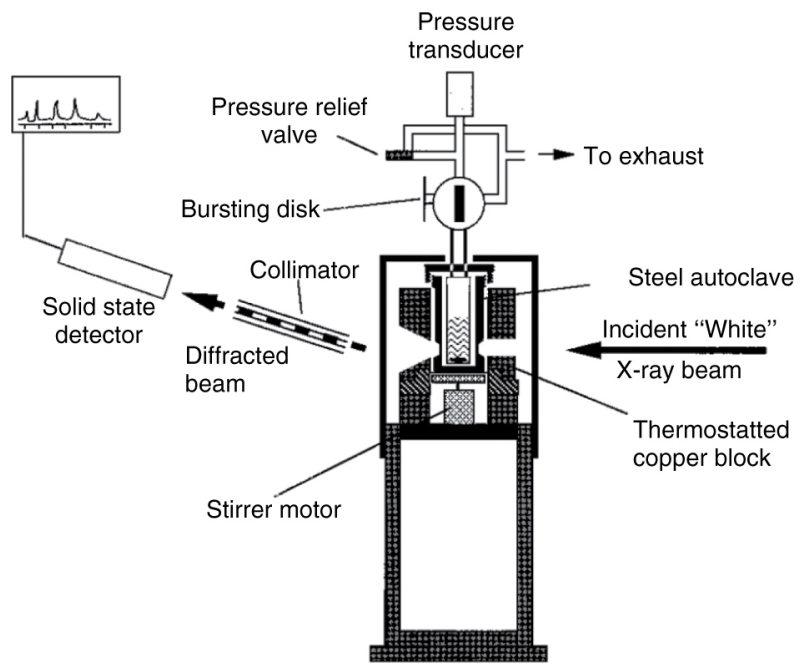

Figure 7: Schematic representation of the setup applied for in situ EDXRD analysis during hydrothermal synthesis of $\left(\mathrm{NMe}_{4}\right)_{2} \mathrm{Sn}_{3} \mathrm{~S}_{7} \bullet x \mathrm{H}_{2} \mathrm{O}$ (Francis et al. 1996). Reprinted with permission from Francis et al. (1996). Copyright 1996 American Chemical Society.

\section{Polyoxo- and chalcogenide metallates}

In addition to complexes, $\mathrm{CP}$ and porous materials, the literature also reports the use of in situ XRD for monitoring metal-ligand exchange processes during synthesis of polyoxo- and chalcogenide metallates. Chalcogenide 
metallate materials such as thiostanates and thioantimonates are interesting due to their tunable optical band gap, photoconductivity and highly variable structural chemistry (Seidlhofer et al. 2012), reviewed in detail by Seidlhofer, Pienack, and Bensch (2010).

More recently, in situ energy dispersive XRD experiments at beamline F3 of the HASYLAB facility (DESY) have been reported for monitoring the solvothermal synthesis of two additional polyoxovanadates (Figure 8, Antonova et al. 2012). In this work, $\mathrm{NH}_{4} \mathrm{VO}_{3}$ and $\mathrm{Sb}_{2} \mathrm{O}_{3}$ were added to an aqueous solution of aep (aep = 1(2-aminoethyl)-piperazine) in a sealed glass tube and, under stirring conditions, heated to a temperature ranging from $150^{\circ} \mathrm{C}$ to $170^{\circ} \mathrm{C}$. Three different compounds were obtained for different aep concentrations: $\left[\mathrm{V}_{14} \mathrm{Sb}_{8}{ }^{-}\right.$ (aep) $\left.\mathrm{O}_{42}\left(\mathrm{H}_{2} \mathrm{O}\right)\right] \cdot 4 \mathrm{H}_{2} \mathrm{O}$ for $75 \%$ aep, phase mixed with (aep) ${ }_{2}\left[\mathrm{~V}_{15} \mathrm{Sb}_{6}(\text { aep })_{2} \mathrm{O}_{42}\left(\mathrm{H}_{2} \mathrm{O}\right)\right] \cdot 2.5 \mathrm{H}_{2} \mathrm{O}$ for $75-80 \%$ aep and $\{\text { aep }\}_{4}\left[\mathrm{~V}_{16} \mathrm{Sb}_{4} \mathrm{O}_{42}\right] 2 \mathrm{H}_{2} \mathrm{O}$ for an aep concentration above $80 \%$. The in situ results revealed that at $77.5 \%$ aep, (aep) ${ }_{2}\left[\mathrm{~V}_{15} \mathrm{Sb}_{6}(\text { aep })_{2} \mathrm{O}_{42}\left(\mathrm{H}_{2} \mathrm{O}\right)\right] \cdot 2.5 \mathrm{H}_{2} \mathrm{O}$ was initially formed, followed by the crystallization of $\left[\mathrm{V}_{14} \mathrm{Sb}_{8}-\right.$ (aep) $\left.{ }_{4} \mathrm{O}_{42}\left(\mathrm{H}_{2} \mathrm{O}\right)\right] \cdot 4 \mathrm{H}_{2} \mathrm{O}$. According to the authors, this behavior is expected, due to the high concentration of aep-amine in the beginning of the reaction, reducing the $\mathrm{V}^{\mathrm{V}}$ to $\mathrm{V}^{\mathrm{IV}}$ and allowing for the formation of the $\left[\mathrm{V}_{15} \mathrm{Sb}_{6} \mathrm{O}_{42}\right]^{6-}$ cluster. After the gradual consumption of the aep amine, the crystallization of the $\left[\mathrm{V}_{14} \mathrm{Sb}_{8} \mathrm{O}_{42}\right]^{4-}$ cluster is able to proceed, with a lower number of reduced vanadium ions. As the reaction temperature increased, the incubation time was reduced (Antonova et al. 2012).

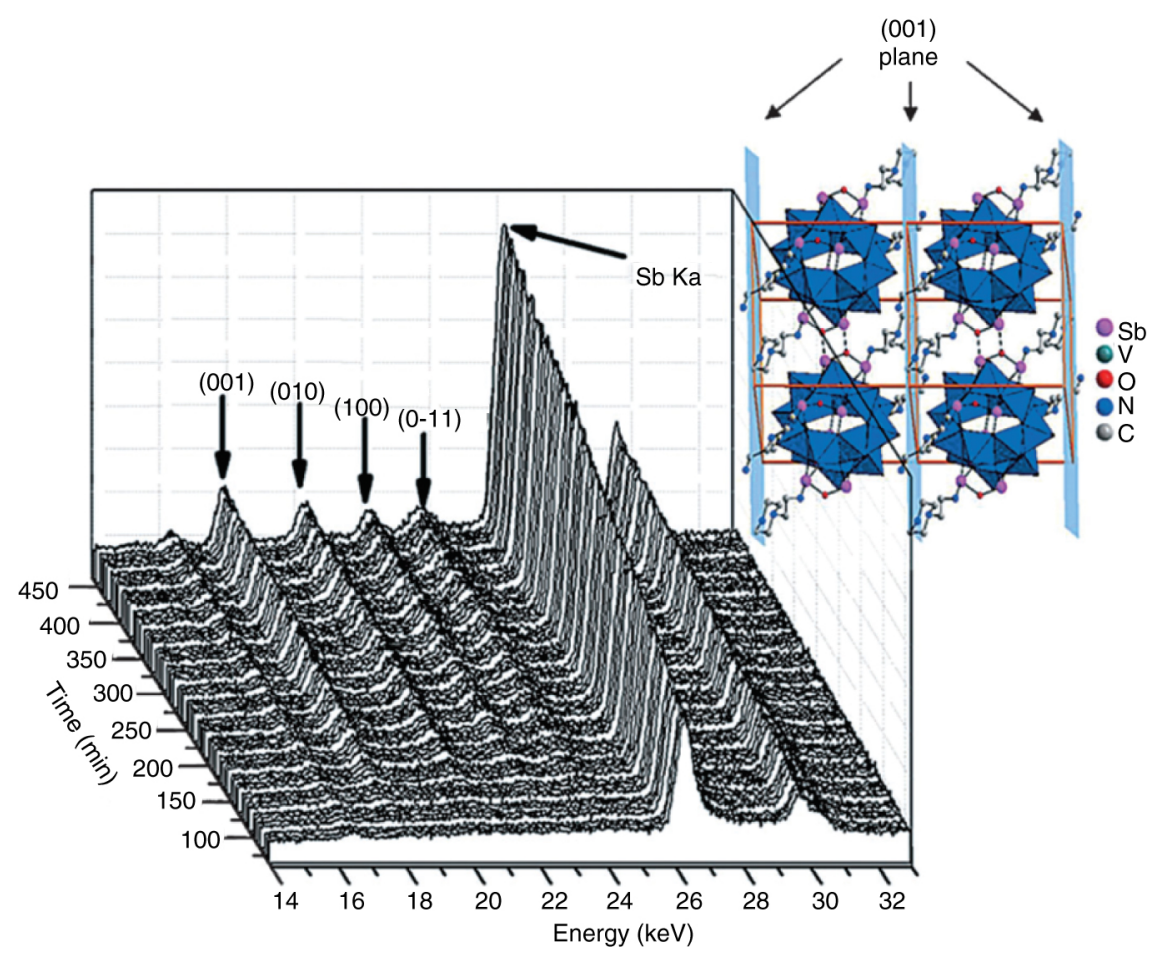

Figure 8: In situ EDXRD patterns recorded during synthesis of $\left[\mathrm{V}_{14} \mathrm{Sb}_{8}-\left(\mathrm{C}_{6} \mathrm{H}_{15} \mathrm{~N}_{3}\right)_{4} \mathrm{O}_{42}\left(\mathrm{H}_{2} \mathrm{O}\right)\right] \cdot 4 \mathrm{H}_{2} \mathrm{O}$ at $160^{\circ} \mathrm{C}$ (Antonova et al. 2012). Copyright Wiley-VCH Verlag GmbH \& Co. KGaA. Reproduced with permission.

The synthesis of two new thiostanates $(\mathrm{DBNH})_{2} \mathrm{Sn}_{3} \mathrm{~S}_{6}$ and $(\mathrm{DBNH})_{2} \mathrm{Cu}_{6} \mathrm{Sn}_{2} \mathrm{~S}_{8} \quad(\mathrm{DBN}=1,5-$ diazabicyclo[4.3.0]non-7-ene) by means of solvothermal synthesis was also monitored by in situ EDXRD by Pienack, Näther, and Bensch in 2009. These experiments were carried out at the HASYLAB F3 beamline at the DESY. These complexes were formed as a result of the reaction of elemental copper, tin and sulfur with 1,5-diazabicyclo[4.3.0]non-5-ene, which also served as a solvent and structure-directing agent. Interestingly, it was found that $(\mathrm{DBNH})_{2} \mathrm{Cu}_{6} \mathrm{Sn}_{2} \mathrm{~S}_{8}$ could not be prepared as a pure phase, with the in situ results demonstrating that $(\mathrm{DBNH})_{2} \mathrm{Sn}_{3} \mathrm{~S}_{6}$ and $(\mathrm{DBNH})_{2} \mathrm{Cu}_{6} \mathrm{Sn}_{2} \mathrm{~S}_{8}$ start to crystallize in a very narrow time window following the formation of a non-identified metastable reaction intermediate. As expected, the formation of $(\mathrm{DBNH})_{2} \mathrm{Sn}_{3} \mathrm{~S}_{6}$ was delayed in the presence of $\mathrm{Cu}$, due to the formation of the side product $(\mathrm{DBNH})_{2} \mathrm{Cu}_{6} \mathrm{Sn}_{2} \mathrm{~S}_{8}$, but formed rapidly in the presence of only Sn, S and DBN (Pienack, Näther, and Bensch 2009).

Seidlhofer et al. (2012) reported data on the crystallization of the thioantimonate $\left[\mathrm{M}(\operatorname{tren}) \mathrm{Sb}_{4} \mathrm{~S}_{7}\right](\mathrm{M}=\mathrm{Fe}$, $\mathrm{Zn}$; tren = tris(2-aminoethyl)amine), studied by in situ EDXRD at the HASYLAB F3 beamline at the DESY. In these experiments, metallic $\mathrm{Zn}$ and $\mathrm{Fe}$ or $\mathrm{FeCl}_{3}$ were reacted with a tren solution under solvothermal conditions in a glass reactor, with stirring. Specifically, the influence of the amine concentration on the formation of ironbased compounds was examined (Seidlhofer et al. 2012). Utilizing a 60\% tren solution, the formation of an unknown crystalline side product in parallel to $\left[\mathrm{Fe}(\operatorname{tren}) \mathrm{Sb}_{4} \mathrm{~S}_{7}\right]$ was observed. When the tren concentration was increased to $70-90 \%$, the unknown side product was formed at the beginning of the reaction, again in parallel to 
$\left[\mathrm{Fe}\right.$ (tren) $\left.\mathrm{Sb}_{4} \mathrm{~S}_{7}\right]$, after which it disappeared and a new $\mathrm{Fe}^{3+} / \mathrm{Fe}^{2+}$ mixed-valent $\left[\mathrm{Fe}\left(\right.\right.$ tren)FeSbS${ }_{4}$ thioantimonate crystallized. Upon increasing the tren concentration to $100 \%$, only [Fe(tren)FeSbS $\mathrm{S}_{4}$ was formed. The correlation between the disappearance of the unknown intermediate and the formation of $\left[\mathrm{Fe}(\mathrm{tren}) \mathrm{FeSbS} \mathrm{S}_{4}\right]$ is explained by the authors as likely to stem from the influence of the $\mathrm{Fe}^{3+} / \mathrm{Fe}^{2+}$ redox reaction, probably caused by the reducing effect of the amine. The unknown compound could not be isolated for further analytical ex situ methods, such as single crystal XRD for determination of its structure. In the analogous experiments utilizing Zn, no crystalline intermediate was detected, likely because $\mathrm{Zn}^{2+}$ is not redox active (Seidlhofer et al. 2012).

One final example focused on the synthesis of $[\mathrm{Co}(\operatorname{tren})]\left[\mathrm{Sb}_{2} \mathrm{~S}_{4}\right]$ under solvothermal conditions, which was monitored by both in situ EDXRD and in situ EXAFS (extended XAS fine structure) by Kiebach et al. in 2006. In these experiments, elemental cobalt, antimony and sulfur were added to a $50 \%$ tren solution at temperatures ranging from $105^{\circ} \mathrm{C}$ to $130^{\circ} \mathrm{C}$ in autoclaves containing glass liners $(d=10 \mathrm{~mm}, V=10 \mathrm{ml})$, with stirring. The mechanism of formation which could be deduced from the in situ data begins with the rapid dissolution of the reactants as the $\mathrm{Co}$ is coordinated by the amine, most likely forming [Co(tren) $]^{2+}$ complexes, indicated by a single XRD reflection. Subsequently, monomeric $\mathrm{SbS}_{x}$ units form, indicated by the simultaneous appearance of several reflection signals, which aggregate into an amorphous precipitate. In the beginning of the reaction, only a single reflection rises, while the other reflections grow simultaneously afterward. A possible explanation for this fact is that the crystallization process begins in disordered layers, later establishing a three-dimensional long-range order (Kiebach et al. 2006).

\section{Technical aspects of multiple combinations of in situ characterization methods}

To understand fully the complex phenomena occurring during formation and dissolution of solid materials in liquid media, it is essential to obtain information not only about what happens inside the solid material but also about what happens in the surrounding solutions. For this reason, it is very advantageous to simultaneously employ multiple in situ characterization techniques in order to complement and confirm the respective results. Different works have recently been reported in the literature which utilize this approach (Pienack et al., 2016a; Pienack, Terraschke \& Bensch, 2016b; Terraschke et al., 2016). The experiments reported in these examples primarily utilize two different setups. The first one consists of a stationary laboratory setup combining an EasyMax ${ }^{\circledR} 102$ (Mettler Toledo) synthesis workstation with automatic temperature control $\left(-25^{\circ} \mathrm{C}\right.$ to $180^{\circ} \mathrm{C}$ ) and dosing system, equipped with a glass reactor $(50$ and $100 \mathrm{ml})$, for syntheses at atmospheric conditions, and a stainless steel reactor, for solvothermal synthesis (Pienack et al. 2016a and Pienack, Terraschke, and Bensch 2016b. The glass reactors enable the measurement of in situ pH, conductivity, redox potential, luminescence spectroscopy and attenuated total reflection Fourier transform IR (Terraschke et al. 2016). When luminescence measurements are performed, these usually utilize a Horiba Jobin Yvon Fl-22 Fluorolog3 luminescence spectrometer, equipped with a Syncerity CCD detector for the high time resolution of the spectra. As outlined in Section "Luminescence", the luminescence spectrometer is attached to the reactor system by means of a Y-formed glass fiber, which simultaneously transports excitation and emission light (Pienack et al., 2016a; Pienack, Terraschke \& Bensch, 2016b).

For the second setup, which is exclusively employed for experiments carried out in synchrotron facilities such as the DESY (PETRA III) or SOLEIL, a modified version of the $50 \mathrm{ml}$ glass reactor is utilized (Figure 9). In order to decrease the length of the pathway, which the synchrotron radiation must transverse through the solvent volume, the modified reactor vessel possesses an indented glass tube through the reaction vessel. Similar to the previously described SynRAC reactor (Figure 5, Reinsch et al. 2017), this glass reactor is placed in a reactor holder with integrated heating and stirring systems specifically designed to quickly fit several beamlines without requiring realignment after each reaction. The reactor holder contains two openings for the entrance and exit of X-ray beams as well as a larger opening arranged at $90^{\circ}$ to the $X$-ray path to allow the irradiation with UV LEDs during luminescence measurements. Luminescent output by reactants and products is detected by means of an optical fiber submersed in the reactor content, which is connected to a CCD detector (Section "Luminescence"). Figure 10 shows two different setups utilized for in situ monitoring of metal-ligand exchange processes involved in the formation and decomposition of the $\left[\mathrm{Eu}(\mathrm{phen})_{2}\left(\mathrm{NO}_{3}\right)_{3}\right]$ complex (Figure 1, Terraschke et al. 2016). 

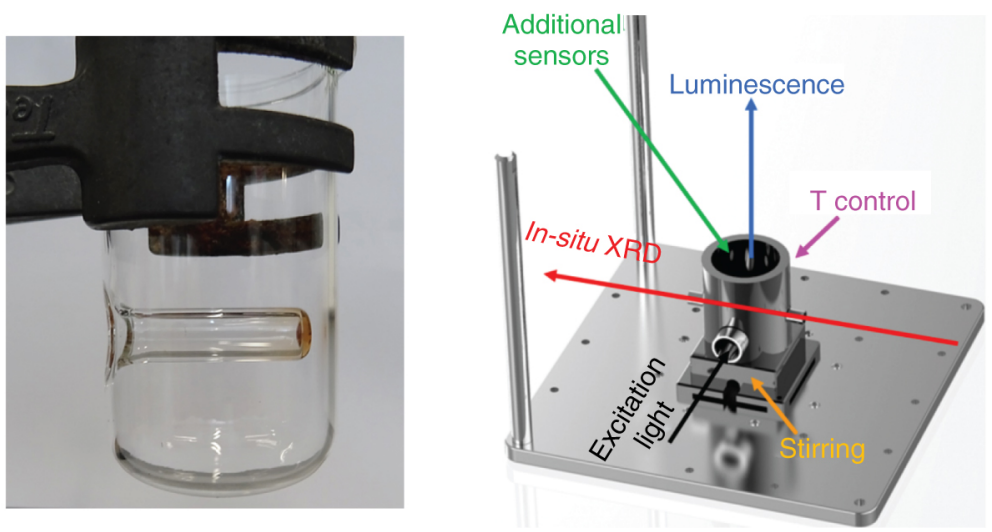

Figure 9: Adaptation of a glass reactor with an indented glass tube to reduce the length of the synchrotron radiation's pathway through the solvent volume (left) and modified reactor holder allowing the combination of in situ XRD with in situ luminescence and additional sensors (right). Reproduced with permission of Pienack et al. (2016a) and Pienack, Terraschke, and Bensch (2016b).
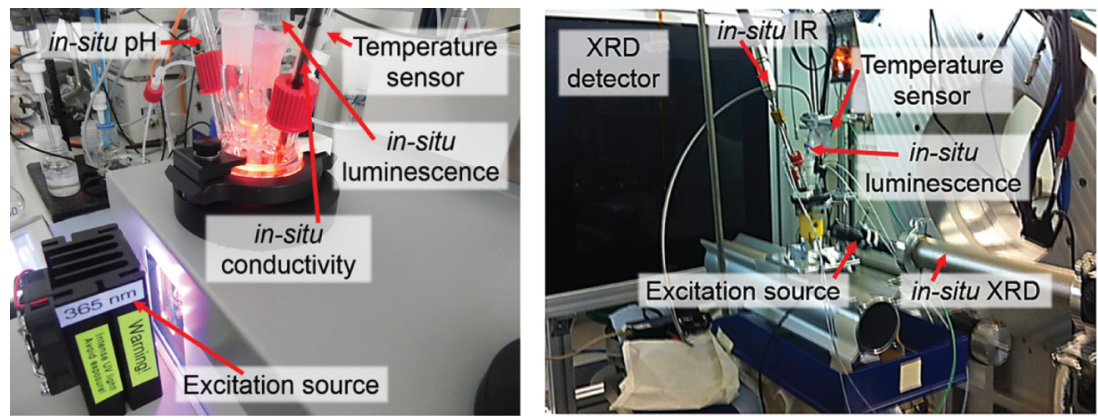

Figure 10: Experimental setup for combining in situ luminescence spectroscopy with in situ measurements of $\mathrm{pH}$ and conductivity (left) as well as with in situ XRD and infrared spectroscopy at the P09 DESY beamline (right). Reproduced with permission from Terraschke et al. (2016).

\section{Conclusions}

The present review summarizes the most recent and relevant developments in the monitoring of metal-ligand exchange processes during formation, phase transitions and decomposition of a variety of materials by in situ measurements of optical properties, XRD analysis or both. In order to monitor the optical properties of reactions in situ, a number of methods can be employed, including recording time-resolved luminescence spectra by ILACS, TRLFS and light absorption or light transmission spectroscopy. ILACS is more appropriate for complex reactions because it allows for utilization of an external reactor, which can reproduce real reaction conditions (e.g. dosing, cooling, heating or stirring). ILACS is also very mobile and easily combined with other in situ techniques. TRLFS is very useful for monitoring more simple reactions in cuvettes, especially for the measurement of luminescence lifetime. However, this method necessitates the use of laser light, offering a rather limited variety of excitation wavelengths, making it less flexible. Requiring access to lasers for excitation energy also limits the mobility of TRLFS setups. For experiments containing no components with inherent luminescent properties, in situ light absorption and transmission spectroscopies are more applicable. An important issue for the application of in situ spectroscopy approaches is the design of the reactor. If the spectrum of, for example, the emitted or transmitted light is measured from outside the reaction vessel, the reactor walls must be optically transparent for the recorded spectral range. Similarly, the reactor walls must be transparent toward the excitation wavelength for in situ luminescence and toward the transmitted light for UV/VIS absorption and transmission spectroscopic approaches. In situ XRD measurements in solutions require high-flux and high-energy X-rays, produced in synchrotron facilities. These high-energy $X$-rays are necessary to allow efficient penetration of the walls of the reaction vessels as well as the solvent bulk. Different types of reactors can be utilized to maximize the accuracy of obtained data from XRD while meeting the specific challenges of the reaction of interest, for instance, the SynRAC setup developed at the University of Kiel for monitoring solvothermal syntheses. The most complete in situ data may be obtained through the simultaneous use of several methods, allowing simultaneous insights into both the solid compounds and the surrounding solution. Such in situ methods have been 
employed to monitor the reactions underlying chemical reactions involving complexes, $\mathrm{CP}, \mathrm{MOFs}$, polyoxo- and chalcogenide metallates, providing interesting insights.

Despite the extensive developments already achieved in this field, there is still a lot to be done. For instance, most of the literature discussed here focused on the application of in situ techniques to investigate either mechanisms of co-precipitation or solvothermal reactions. Little work has been completed utilizing other types of syntheses, such as ultrasound, ionic liquid or polyol-based approaches. In addition, improvements in the noise-to-signal ratio of in situ XRD data are still necessary, perhaps through the integration of the so-called serial crystallography method for inorganic or hybrid organic-inorganic materials (Beyerlein et al. 2015). Finally, experiments using synchrotron radiation as in situ XRD are still seen by many chemistry research groups as something intangible. Constructing especially designed reactors can be expensive or time consuming and experience on writing proposals or performing experiments at the beamlines is of great advantage. However, these challenges can be easily overcome by means of fruitful collaborations, for instance, with the research groups mentioned in this review. In addition, it is of interest for the synchrotron facilities to expand the application of synchrotron radiation within the chemistry community. Therefore, the present review could hopefully motivate other scientists to not only concentrate on the ex situ characterization of their final products but also on understanding what is happening inside the reactions, especially applying the exciting new techniques presented here.

\section{Acknowledgments}

The authors would like to thank the German Research Foundation (project TE 1147/1-1), the Daimler and Benz Foundation and the MATsynCELL Consortium for financial support.

\section{References}

Ahnfeldt, T., \& Stock, N. (2012). Synthesis of isoreticular CAU-1 compounds: effects of linker and heating methods on the kinetics of the synthesis. CrystEngComm, 14, 505-511.

Ahnfeldt, T., Moellmer, J., Guillerm, V., Staudt, R., Serre, C., \& Stock, N. (2011). High-throughput and time-resolved energy-dispersive X-Ray diffraction (EDXRD) study of the formation of CAU-1-(OH $)_{2}$ : microwave and conventional heating. Chemistry A European Journal, 17 , 6462-6468.

Albinati, A., Bakhmutov, V. I., Belkova, N. V., Bianchini, C., De los Rios, I., Epstein, L., ... Zanobini, F. (2002). Synthesis, characterization, and interconversion of the rhenium polyhydrides $\left[\operatorname{ReH}_{3}\left(\eta_{4}-\mathrm{NP}_{3}\right)\right]$ and $\left[\mathrm{ReH}_{4}\left(\eta_{4}-\mathrm{NP}_{3}\right)\right]^{+}\left\{\mathrm{NP}_{3}=\operatorname{tris}[2\right.$-(diphenylphosphanyl)ethyl]amine $\}$. European Journal of Inorganic Chemistry, 6, 1530-1539.

Antonova, E., Seidlhofer, B., Wang, J., Hinz, M., \& Bensch, W. (2012). Controlling nucleation and crystal growth of a distinct polyoxovanadate cluster: an in-situ energy dispersive X-ray diffraction study under solvothermal conditions. Chemistry A European Journal, 18, 15316-15322.

Asanova, T. I., Asanov, I. P., Kim, M.-C., Gerasimov, E. Y., Zadesenets, A. V., Plyusnin, P. E., \& Korenev, S. V. (2013). On formation mechanism of $\mathrm{Pd}-\mathrm{Ir}$ bimetallic nanoparticles through thermal decomposition of $\left.\left[\mathrm{Pd}\left(\mathrm{NH}_{3}\right)_{4}\right][\mathrm{IrCl}]_{6}\right]$. Journal of Nanoparticle Research, 15, 1994/1-15.

Avrami, M. (1939). Kinetics of phase change. I general theory. Journal ofChemical Physics, 7, 1103.

Avrami, M. (1940). Kinetics of phase change. Il transformation-time relations for random distribution of nuclei. Journal ofChemical Physics, 8 , 212.

Avrami, M. (1941). Cranulation, phase change, and microstructure kinetics of phase change. III. Journal ofChemical Physics, 9, 177.

Bae, S., Han, Seung J., Shin, Tae J., \& Jo, W. H. (2015). Two different mechanisms of $\mathrm{CH}_{3} \mathrm{NH}_{3} \mathrm{Pbl}_{3}$ film formation in one-step deposition and its effect on photovoltaic properties of OPV-type perovskite solar cells. Journal of Materials Chemistry A, 3, 23964-23972.

Barthelemy, P. P., \& Choppin C. R. (1989). Luminescence study of complexation of europium and dicarboxylic acids. Inorganic Chemistry, 28, 3354-3357.

Bauer, M., \& Bertagnolli, H. (2009). Towards X-ray absorption spectroscopy in real time. ChemPhysChem, 10, 2197-2200.

Bauer, M., \& Gastl, C. (2010). X-ray absorption in homogeneous catalysis research: the iron-catalyzed Michael addition reaction by XAS, RIXS and multi-dimensional spectroscopy. Physical Chemistry Chemical Physics, 12, 5575-5584.

Beyerlein, K. R., Jooss, C., Barty, A., Bean, R., Boutet, S., Dhesi, S. S., ... Chapman, H. N. (2015). Trace phase detection and strain characterization from serial X-ray free-electron laser crystallography of a $\mathrm{Pr}_{0.5} \mathrm{Ca}_{0.5} \mathrm{MnO}_{3}$ powder. ICCD, 30, S25-S30.

Binnemans, K. (2015). Interpretation of europium(III) spectra. Coordination Chemistry Reviews, 295, 1-45.

Braga, D., Grepioni, F., Maini, L., \& Polito, M. (2009). Crystal polymorphism and multiple crystal forms. In M. W. Hosseini (Ed.), Molecular networks (Vol. 132, pp. 25-50). Berlin: Springer Verlag.

Buckau, G., Kim, J. I., Klenze, R., Rhee, D. S., \& Wimmer, H. (1992). A comparative spectroscopic study of the fulvate complexation of trivalent transuranium ions. Radiochimica Acta Radiochim, 57, 105-111.

Chang S., Karambelkar V. V., Sommer R. D., Rheingold A. L., \& Goldberg, D. P. (2002). New monomeric cobalt(II) and zinc(II) complexes of a mixed N,S(alkylthiolate) ligand: model complexes of (His)(His)(Cys) metalloprotein active sites. Inorganic Chemistry, 41, $239-248$.

Coffey, P. (2008). From Cathedrals of science: the personalities and rival ries that made modern chemistry. Oxford, UK: Oxford University Press. 
Cornel, J., Lindenberg, C., \& Mazzotti, M. (2008). Quantitative application of in situ ATR-FTIR and Raman spectroscopy in crystallization processes. Industrial and Engineering Chemistry Research, 47, 4870-4882.

Elder, R. C., Lunte, C. E., Rahman, A. F. M. M., Kirchhoff, J. R., Dewald, H. D., \& Heineman, W. R. (1988). In-situ observation of copper redox in a polymer modified electrode using EXAFS spectroelectrochemistry. Journal of Electroanalytical Chemistry and Interfacial Electrochemistry, 240, 361-364

El Osta, R., Frigoli, M., Marrot, J., Medina, M. E., Walton, R. I., \& Millange, F. (2012). Synthesis, structure, and crystallization study of a layered lithium thiophene-dicarboxylate. Crystal Crowth and Design, 12, 1531-1537.

El Osta, R., Feyand, M., Stock, N., Millange, F., \& Walton, R. I. (2013) Crystallisation kinetics of metal organic frameworks from in situ timeresolved X-ray diffraction. Powder Diffraction, 28, S256-S275.

Engelke, L., Schaefer, M., Porsch, F., \& Bensch, W. (2003). In-situ energy-dispersive X-ray diffraction studies of crystal growth and compound conversion under solvothermal conditions. European Journal of Inorganic Chemistry, 3, 506-513.

Férey, G., Haouas, M., Loiseau, T., \& Taulelle, F. (2014). Nanoporous solids: how do they form? An in situ approach. Chemistry of Materials, 26, 299-309.

Feyand, M., Näther, C., Rothkirch, A., \& Stock, N. (2010). Systematic and in-situ energy dispersive X-ray diffraction investigations on the formation of lanthanide phosphonatobutanesulfonates: $\mathrm{Ln}\left(\mathrm{O}_{3} \mathrm{P}-\mathrm{C}_{4} \mathrm{H}_{8}-\mathrm{SO}_{3}\right)\left(\mathrm{H}_{2} \mathrm{O}\right)(\mathrm{Ln}=\mathrm{La}-\mathrm{Cd})$. Inorganic Chemistry, 49, 11158-11163.

Feyand, M., Huebner, A., Rothkirch, A., Wragg, D. S., Stock, N. (2012). Copper phosphonatoethanesulfonates: temperature dependent in situ energy dispersive $\mathrm{X}$-ray diffraction study and influence of the $\mathrm{pH}$ on the crystal structures. Inorganic Chemistry, 51, 12540-12547.

Feyand, M., Koeppen, M., Friedrichs, G., \& Stock, N. (2013). Bismuth tri- and tetraarylcarboxylates: crystal structures, in-situ X-ray diffraction, intermediates and luminescence. Chemistry A European Journal, 19, 12537-12546.

Fitzgerald, M., Pappas, I., Zheng, C., Xie, Z.-L., Huang, X.-Y., Tao, S., \& Pan, L. (2009). First hexanuclear zirconium macrocycle sustained in a chair-like conformation by glycolic acids. Dalton Transactions, 32, 6289-6291.

Francis, R. J., Price, S. J., Evans, J. S. O., O'Brien, S., O'Hare, D., \& Clark, S. M. (1996). Hydrothermal synthesis of microporous tin sulfides studied by real-time in-situ energy-dispersive X-ray diffraction. Chemistry of Materials, 8, 2102-2108.

Gade, L. H. (2010). From Koordinationschemie. Weinheim, Germany: Wiley-VCH.

Ceipel, G. (2006). Some aspects of actinide speciation by laser-induced spectroscopy. Coordination Chemistry Reviews, 250, 844-854.

Geipel, G., Brachmann, A., Brendler, V., Bernhard, G., \& Nitsche, H. (1996). Uranium(VI) sulfate complexation studied by time-resolved laserinduced fluorescence spectroscopy (TRLFS). Radiochimica Acta Radiochim, 75, 199-204.

Gualtieri, A. F. (2001). Synthesis of sodium zeolites from a natural halloysite. Physics and Chemistry of Minerals, 28, 719-728.

Gustafsson, M., Li, Z., Zhu, G., Qiu, S., Grins, J., \& Zou, X. (2008). A porous chiral lanthanide metal-organic framework with high thermal stability. Studies in Surface Science and Catalysis, 174A, 451-454.

Hafshejani, L. D., Tangsir, S., Koponen, H., Riikonen, J., Karhunen, T., Tapper, U., ... Hooshmand, A. (2016). Synthesis and characterization of $\mathrm{Al}_{2} \mathrm{O}_{3}$ nanoparticles by flame spray pyrolysis (FSP) - Role of Fe ions in the precursor. Powder Technology, 298, 42-49.

Hancock, J. D., \& Sharp, J. H. (1972). Method of comparing solid-state kinetic data and its application to the decomposition of kaolinite, brucite, and $\mathrm{BaCO}_{3}$. Journal of the American Ceramic Society, 55, 74 .

Haouas, M., Volkringer, C., Thierry, L., Cérard, F., \& Francis, T. (2012). In-situ NMR, ex-situ XRD and SEM study of the hydrothermal crystallization of nanoporous aluminum trimesates MIL-96, MIL-100, and MIL-110. Chemistry of Materials, 24, 2462-2471.

Haraguchi, T., Otsubo, K., Sakata, O., Fujiwara, A., \& Kitagawa, H. (2016). Guest-induced two-way structural transformation in a layered metal-organic framework thin film. Journal of the American Chemical Society, 138, 16787-16793.

Heidenreich, N., Rütt, U., Köppen, M., Ken Inge, A., Dippel, A.-C., Suren, R., \& Stock N. (2017,). SynRAC-A multi-purpose reaction cell for the investigation of reactions under solvothermal conditions. manuscript in preparation.

Hollingsworth, N., Roffey, A., Islam, H.-U., Mercy, M., Roldan, A., Bras, W., ... de Leeuw, N. H. (2014). Active nature of primary amines during thermal decomposition of nickel dithiocarbamates to nickel sulfide nanoparticles. Chemistry of Materials, 26, 6281-6292.

Inge, A. K., Peskov, M. V., Sun, J., \& Zou, X. (2012). SU-62: synthesis and structure investigation of a germanate with a novel three-dimensional net and interconnected 10- and 14-ring channels. Crystal Growth and Design, 12, 369-375.

Jensen, K. M. Ф., Christensen, M., Juhas, P., Tyrsted, C., Bøjesen, E. D., Lock, N., ... Iversen, B. B. (2012). Revealing the mechanisms behind SnO nanoparticle formation and growth during hydrothermal synthesis: an in situ total scattering study. Journal of the American Chemical Society, 134, 6785-6792.

Jensen, K. M. Ø., Tyrsted, C., Bremholm, M., \& Iversen, B. B. (2014). In-situ studies of solvothermal synthesis of energy materials. ChemSusChem, 7,1594-1611.

Jin, G. B. (2016). Three-dimensional network of cation-cation-bound Neptunyl(V) squares: synthesis and in-situ Raman spectroscopy studies. Inorganic Chemistry, 55, 2612-2619.

Jung, D. R., \& Czanderna, A. W. (1994). Metal overlayers on organic functional groups of self-organized molecular assemblies. III. X-ray photoelectron spectroscopy of $\mathrm{Cr} / \mathrm{CN}$ on 12-mercaptododecanenitrile and of $\mathrm{Cr} / \mathrm{CH} 3$ on octadecanethiol at low temperatures from 173 to $373 \mathrm{~K}$. Journal of Vacuum Science \& Technology, A: Vacuum, Surfaces, and Films, 12, 2402-2409.

Kato, Y., Meinrath, G., Kimura, T., \& Yoshida, Z. (1994). A study of U(VI) hydrolysis and carbonate complexation by time-resolved laserinduced fluorescence spectroscopy (TRLFS). Radiochimica Acta Radiochim, 64, 107-111.

Keating, J., Sankar, G., Hyde, T. I., Koharac, S., \& Ohara, K. (2013). Elucidation of structure and nature of the PdO-Pd transformation using in situ PDF and XAS techniques. Physical Chemistry Chemical Physics, 15, 8555-8565.

Kiebach, R., Schaefer, M., Porsch, F., \& Bensch, W. (2005). In-situ energy dispersive X-ray diffraction studies of the crystallization of (1,2$\left.\mathrm{DAPH}_{2}\right)_{2} \mathrm{Ce}_{9}(\mathrm{OH})_{4} \mathrm{O}_{18} \cdot 2 \mathrm{H}_{2} \mathrm{O}$ under solvothermal conditions. Zeitschrift für Anorganische und Allgemeine Chemie, 631, 369-374.

Kiebach, R., Pienack, N., Ordolff, M.-E., Studt, F., \& Bensch, W. (2006). Combined in-situ EDXRD/EXAFS investigation of the crystal growth of $\left[\mathrm{Co}\left(\mathrm{C}_{6} \mathrm{H}_{18} \mathrm{~N}_{4}\right)\right]\left[\mathrm{Sb}_{2} \mathrm{~S}_{4}\right]$ under solvothermal conditions: two different reaction pathways leading to the same product. Chemistry of Materials, 18, 1196-1205.

Kim, J. I., Wimmer, H., \& Klenze, R. (1991). A study of curium(III) humate complexation by time resolved laser fluorescence spectroscopy (TRLFS). Radiochimica Acta Radiochim, 54, 35-41. 
Kim, J. S., Marzouk, H. A., Reucroft, P. J., Robertson, J. D., \& Hamrin, C. E. (1993). Fabrication of aluminum oxide thin films by a low-pressure metalorganic chemical vapor deposition technique. Applied Physics Letters, 62, 681.

Kitagawa, S., Kitaura, R., \& Noro, S.-I. (2004). Funktionale poröse Koordinationspolymere. Angewandte Chemie, 116, 2388-2430.

Kubanek, P., Busch, O., Thomson, S., Schmidt, H. W., \& Schüth, F. (2004). Imaging Reflection IR Spectroscopy as a tool to achieve higher integration for high-throughput experimentation in catalysis research. Journal of Combinatorial Chemistry, 6, 420-425.

Kubanek, P., Schmidt, H.-W., Spliethoff, B., \& Schüth, F. (2005). Parallel IR spectroscopic characterization of CO chemisorption on Pt loaded zeolites. Microporous and Mesoporous Materials, 77, 89-96.

Lammert, M., Reinsch, H., Murray, C. A., Wharmby, M. T., Terraschke, H., \& Stock, N. (2016). Synthesis and structure of Zr(IV)- and Ce(IV)based CAU-24 with 1,2,4,5-tetrakis(4-carboxyphenyl)benzene. Dalton Transactions, 45, 18822-18826.

Lei, L., Jing, S., Walton, R. I., Xin, X., \& O'Hare, D. (2002). Investigation of the solid-state reaction of $\mathrm{FeSO}_{4} \cdot 7 \mathrm{H}_{2} \mathrm{O}$ with 1,10-phenanthroline. Dalton Transactions, 18, 3477-3481.

Lestari, W. W., Lönnecke, P., Streit, H. C., Handke, M., Wickleder, C., \& Hey-Hawkins, E. (2014a). A chiral two-dimensional coordination polymer based on Cull and (S)-4,4'-bis(4-carboxyphenyl)-2,2' -bis(diphenylphosphinoyl)-1,1'-binaphthyl: Synthesis, structure, and magnetic and optical properties. European Journal of Inorganic Chemistry, 10, 1775-1782.

Lestari, W. W., Lönnecke, P., Streit, H. C., Schleife, F., Wickleder, C., \& Hey-Hawkins, E. (2014b). A chiral two-dimensional coordination polymer based on Cull and (S)-4,4'-bis(4-carboxyphenyl)-2,2' -bis(diphenylphosphinoyl)-1,1'-binaphthyl: Synthesis, structure, and magnetic and optical properties. Inorganica Chimica Acta, 421, 392-398.

Lestari, W. W., Streit, H. C., Lönnecke, P., Wickleder, C., \& Hey-Hawkins, E. (2014C). Synthesis, structure and luminescence properties of a cadmium(II)-based coordination polymer with (S)-4,4'-bis(4-carboxyphenyl)-2,2'-bis(diphenylphosphinoyl)-1,1'-binaphthyl as chiral linker. Dalton Transactions, 43, 8188-8195.

Lindenberg, P., Ruiz Arana, L., Heidenreich, N., \& Terraschke, H. (2016). Polymorphism and in-situ detection of reaction intermediates on $\mathrm{Eu}(1,10-\text { Phenanthroline })_{2}\left(\mathrm{NO}_{3}\right)_{3}$. Zeitschrift fur Anorganische und Allgemeine Chemie, 642, 1074.

Loiseau, T., Beitone, L., Millange, F., Taulelle, F., O'Hare, D., \& Ferey, G. (2004). Observation and reactivity of the chainlike species $\left(\left[\mathrm{Al}\left(\mathrm{PO}_{4}\right)_{2}\right]^{3-}\right)_{\mathrm{n}}$ during the $\mathrm{X}$-ray diffraction investigation of the hydrothermal synthesis of the super-sodalite sodium aluminophosphate MIL-74 $\left(\mathrm{Na}_{2} \mathrm{Al}_{7}\left(\mathrm{PO}_{4}\right)_{12} \cdot 4\right.$ tren $\left.\mathrm{H}_{3} \cdot \mathrm{Na}\left(\mathrm{H}_{2} \mathrm{O}\right)_{16}\right)$. Journal of Physical Chemistry B, 108, 20020-20029.

Mann, O., Freyland, W., Raz, O., \& Ein-Eli, Y. (2008). Electrochemical deposition of ultrathin ruthenium films on Au(111) from an ionic liquid. Chemical Physics Letters, 460, 178-181.

Marang, L., Eidner, S., Kumke, M. U., Benedetti, M. F., \& Reiller, P. E. (2009). Spectroscopic characterization of the competitive binding of $\mathrm{Eu}(\mathrm{III}), \mathrm{Ca}(\mathrm{II})$, and $\mathrm{Cu}(\mathrm{II})$ to a sedimentary originated humic acid. Chemical Ceology, 264, 154-161.

Mathur, J. N., Cernochova, K., \& Choppin, G. R. (2007). Thermodynamics and laser luminescence spectroscopy of binary and ternary complexation of $\mathrm{Am}^{3+}, \mathrm{Cm}^{3+}$ and $\mathrm{Eu}^{3+}$ with citric acid, and citric acid +EDTA at high ionic strength. Inorganica Chimica Acta, 360, $1785-1791$.

Mi, J.-L., Jensen, K. M. Ф., Tyrsted, C., Bremholm, M., \& Iversen, B. B. (2015). In-situ total X-ray scattering study of the formation mechanism and structural defects in anatase $\mathrm{TiO}_{2}$ nanoparticles under hydrothermal conditions. CrystEngComm, 17, 6868-6877.

Millange, F., Medina, M. I., Guillou, N., Ferey, G., Golden, K. M., \& Walton, R. I. (2010). Time-resolved in-situ diffraction study of the solvothermal crystallization of some prototypical metal-organic frameworks. Angewandte Chemie International Edition, 49, 763-766.

Moorhouse, S. J., Wu, Y., \& O'Hare, D. (2016). An in-situ study of resin-assisted solvothermal metal-organic framework synthesis. Journal of Solid State Chemistry, 236, 209-214.

Moulin, C., Wei, J., Van Iseghem, P., Laszak, I., Plancque, G., \& Moulin, V. (1999). Europium complexes investigations in natural waters by timeresolved laser-induced fluorescence. Analytica Chimica Acta, 396, 253-261.

Niekiel, F., Ackermann, M., Guerrier, P., Rothkirch, A., \& Stock, N. (2013). Aluminum-1,4-cyclohexanedicarboxylates: high-throughput and temperature-dependent in-situ EDXRD studies. Inorganic Chemistry, 52, 8699-8705.

Nishimura, S., Takagaki, A., Maenosono, S., \& Ebitani, K. (2010). In-situ time-resolved XAFS study on the formation mechanism of Cu nanoparticles using poly(N-vinyl-2-pyrrolidone) as a capping agent. Langmuir, 26, 4473-4479.

$\emptyset$ Øeien, S., Agostini, G., Svelle, S., Borfecchia, E., Lomachenko, K. A., Mino, L., ... Lamberti, C. (2015). Probing reactive platinum sites in UiO-67 zirconium metal-organic frameworks. Chemistry of Materials, 27, 1042-1056.

O'Hare, D., Evans, J. S., Francis, R., Price, S., \& O'Brien, S. (1998). The use of in-situ powder diffraction in the study of intercalation and hydrothermal reaction kinetics. In R. Delhez and E. J. Mittemeijer (Eds.), Materials science forum (Vol. 278, pp. 367-378). Trans Tech Publications.

Otsubo, K., Haraguchi, T., Sakata, O., Fujiwara, A., \& Kitagawa, H. (2012). Step-by-step fabrication of a highly oriented crystalline threedimensional pillared-layer-type metal-organic framework thin film confirmed by synchrotron X-ray diffraction. Journal of the American Chemical Society, 134, 9605-9608.

Panak, P., Klenze, R., Kim, J. I., \& Wimmer, H. (1995). A study of intramolecular energy transfer in Cm(III) complexes with aromatic ligands by time-resolved laser fluorescence spectroscopy. Journal of Alloys and Compounds, 225, 261-266.

Pappas, I., Fitzgerald, M., Huang, X.-Y., Li, J., \& Pan, L. (2009). Thermally resolved in-situ dynamic light scattering studies of zirconium(IV) complex formation. Crystal Crowth and Design, 9, 5213-5219.

Pelster, S. A., Schrader, W., \& Schüth, F. (2006). Monitoring temporal evolution of silicate species during hydrolysis and condensation of silicates using mass spectrometry. Journal of the American Chemical Society, 128, 4310-4317.

Pienack, N., \& Bensch, W. (2011). In-Situ monitoring of the formation of crystalline solids. Angewandte Chemie International Edition, 50, 2014-2034.

Pienack, N., Näther, C., \& Bensch, W. (2009). Solvothermal syntheses of two new thiostannates and an in-situ energy dispersive X-ray scattering study of their formation. European Journal of Inorganic Chemistry, 7, 937-946.

Pienack, N., Ruiz Arana, L., Bensch, W., \& Terraschke H. (2016a). In-situ studies on phase transitions of Tris(acetylacetonato)-aluminum(III) $\mathrm{Al}(\mathrm{acac})_{3}$. Crystals, 6, 157-171.

Pienack, N., Terraschke, H., \& Bensch, W. (2016b). In-situ crystallization cell: developments and first results of the model system Al(acac) . $^{\text {. }}$ Zeitschrift für Anorganische und Allgemeine Chemie, 642, 1040. 
Piskula, Z., Svobodova, I., Lubal, P., Lis, S., Hnatejko, Z., \& Hermann, P. (2007). Kinetic study of dissociation of Eu(III) complex with H8dotp (H8dotp =1,4,7,10-tetraazacyclododecane-1,4,7,10-tetrakis (methylphosphonic acid)). Inorganica Chimica, Acta, 360, 3748-3755.

Polzin, P., Eliani, I. V., \& Terraschke H. (2016). Characterizing the crystallization kinetics of $\operatorname{Ln}\left(2,2^{\prime}-\text { Bipyridine }\right)_{2}\left(\mathrm{NO}_{3}\right)_{3}(\mathrm{Ln}=\mathrm{Eu}, \mathrm{Tb})$ by new in-situ luminescence analysis technique. Zeitschrift für Anorganische und Allgemeine Chemie, 642, 1073.

Procházková, S., Hranícek, J., Kubícek, V., \& Hermann, P. (2016). Formation kinetics of europium(III) complexes of DOTA and its bis(phosphonate) bearing analogs. Polyhedron, 111, 143-149.

Reedijk, J. (2008). Metal-ligand exchange kinetics in platinum and ruthenium complexes. Significance for effectiveness as anticancer drugs. Platinum Metals Review, 52, 2-11.

Reinsch, H., \& Stock, N. (2013). Formation and characterisation of Mn-MIL-100. CrystEngComm, 15, 544-550.

Reinsch, H., Benecke, J., Etter, M., Heidenreicha, N., \& Stock, N. (2017). Combined in- and ex-situ studies of pyrazine adsorption into the aliphatic MOF AI-CAU-13: structures, dynamics and correlations. Dalton Transactions, 46, 1397-1405.

Riahi, S., Ganjali, M. R., Hariri, M., Abdolahzadeh, S., \& Norouzi, P. (2009). Determination of the formation constant for the inclusion complex between Lanthanide ions and Dansyl chloride derivative by fluorescence spectroscopy: Theoretical and experimental investigation. Spectrochimica Acta, Part A: Molecular and Biomolecular Spectroscopy, 74A, 253-258.

Rowsell, J. L. C., \& Yaghi, O. M. (2004). Metal-organic frameworks: a new class of porous materials. Microporous and Mesoporous Materials, 73 , $3-14$.

Saha, D., Bøjesen, E. D., Jensen, K. M. Ф., Dippel, A.-C., \& Iversen, B. B. (2015). Formation mechanisms of Pt and Pt ${ }_{3}$ Cd Nanoparticles under solvothermal conditions: an in-situ total X-ray Scattering Study. Journal of Physical Chemistry C, 119, 13364-13369.

Sarkar, A., Seth, D., Jiang, M., Ng, F. T. T., \& Rempel, C. L. (2014). Active sites of a $\mathrm{NiSO}_{4} / \gamma-\mathrm{Al}_{2} \mathrm{O}_{3}$ catalyst for the oligomerization of isobutene. Topics in Catalysis, 57, 730-740.

Schaack, B. B., Schrader, W., Corma, A., \& Schüth, F. (2009). Nucleation of ITQ-21 studied by ESI-MS. Chemistry of Materials, 21, 4448-4453.

Schilling, L.-H., \& Stock, N. (2014). High-throughput ultrasonic synthesis and in-situ crystallisation investigation of metal phosphonocarboxylates. Dalton Transactions, 43, 414-422.

Schmidt, C., \& Stock, N. (2011). High-throughput and in-situ energy dispersive X-ray diffraction investigation on the formation of the new metal organogermanate $\mathrm{Cu}\left(\mathrm{OOCC}_{2} \mathrm{H}_{4} \mathrm{Ce}\right)_{2} \mathrm{O}_{3}$. Crystal Crowth and Design, 11, 5682-5687.

Schmidt, C., \& Stock, N. (2012). Systematic investigation of zinc aminoalkylphosphonates: influence of the alkyl chain lengths on the structure formation. Inorganic Chemistry, 51, 3108-3118.

Schmidt, C., Feyand, M., Rothkirch, A., \& Stock, N. (2012). High-throughput and in-situ EDXRD investigation on the formation of two new metal aminoethylphosphonates $-\mathrm{Ca}\left(\mathrm{O}_{3} \mathrm{PC}_{2} \mathrm{H}_{4} \mathrm{NH}_{2}\right)$ and $\mathrm{Ca}(\mathrm{OH})\left(\mathrm{O}_{3} \mathrm{PC}_{2} \mathrm{H}_{4} \mathrm{NH}_{3}\right) \cdot 2 \mathrm{H}_{2} \mathrm{O}$. Journal of Solid State Chemistry, 188, 44-49.

Schweinefuß, M. E., Baburin, I. A., Schroeder, C. A., Näther, C., Leoni, S., \& Wiebcke, M. (2014). Indium imidazolate frameworks with differently distorted $\mathrm{ReO}_{3}$-type structures: syntheses, structures, phase transitions, and crystallization studies. Crystal Crowth and Design, 14 , 4664-4673.

Seidlhofer, B., Pienack, N., \& Bensch, W. (2010). Synthesis of inorganic-organic hybrid thiometallate materials with a special focus on thioantimonates and thiostannates and in-situ X-ray scattering studies of their formation. Zeitschrift für Naturforschung B: Journal ofChemical Sciences, 65, 937-975.

Seidlhofer, B., Antonova, E., Wang, J., Schinkel, D., \& Bensch, W. (2012). On the complexity of crystallization of thioantimonates: in-situ energy dispersive X-ray diffraction (EDXRD) studies of the solvothermal formation of the isostructural thioantimonates [TM(tren)Sb $\left.\mathrm{S}_{7}\right]\left(\mathrm{TM}_{7}=\right.$ $\mathrm{Fe}, \mathrm{Zn}$ ). Zeitschrift für Anorganische und Allgemeine Chemie, 638, 2555-2564.

Shubin, Y. V., Korenev, S. V., \& Sharafutdinov, M. R. (2006). High-temperature X-ray diffraction study of thermolysis of the double complex salt $\left[\mathrm{Rh}\left(\mathrm{NH}_{3}\right)_{5} \mathrm{Cl}\right]\left[\mathrm{PtCl}_{4}\right]$. Russian Chemical Bulletin, 55, 1109-1113.

Song, L.-C., Lu, Y., Cao, M., \& Yang, X.-Y. (2016). Reactions of dinuclear $\mathrm{Ni}_{2}$ complexes $\left[\mathrm{Ni}\left(\mathrm{RNPyS}_{4}\right)\right]_{2}\left(\mathrm{RNPyS}_{4}=2,6-\right.$ bis(2-mercaptophenylthiomethyl)-4-R-pyridine) with $\mathrm{Fe}(\mathrm{CO})_{3}(\mathrm{BDA})(\mathrm{BDA}=$ benzylidene acetone) leading to heterodinuclear $\mathrm{NiFe}$ and mononuclear Fe complexes related to the active sites of [NiFe]- and [Fe]-hydrogenases. RSC Advances, 6, 39225-39233.

Stawski, T. M., \& Benning, L. G. (2013). SAXS in inorganic and bioinspired research. Methods in Enzymology, 532, 95-127.

St. John, S., Nan, Z., Hu, N., Schaefer, D. W., \& Angelopoulos, A. P. (2013). A nanoscale-modified LaMer model for particle synthesis from inorganic tin-platinum complexes. Journal of Materials Chemistry A, 1, 8903-8916.

Táborsky, P., Svobodová, I., Lubal, P., Hnatejko, Z., Lis, S., \& Hermann, P. (2007). Formation and dissociation kinetics of Eu(III) complexes with $\mathrm{H}_{5} \mathrm{do}_{3}$ ap and similar dota-like ligands. Polyhedron, 26, 4119-4130.

Tan, X., Fang, M., \& Wang, X. (2010). Sorption speciation of lanthanides/actinides on minerals by TRLFS, EXAFS and DFT studies: a review. Molecules, 15, 8431-8468.

Streit, H. C., Adlung, M., Shekhah, O., Stammer, X., Arslan, H. K., Zybaylo, O. ... Wickleder, C. (2012). Surface-anchored MOF-based photonic antennae. ChemPhysChem, 13, 2699-2702.

Terraschke, H., \& Wickleder, C. (2015). UV, blue, green, yellow, red and small: newest developments on Eü ${ }^{2+}$-doped nanophosphors. Chemical Reviews, 115, 11352-11378.

Terraschke, H., Meier, M. F. T., Voss, Y., Schönherr, H., \& Wickleder, C. (2015a). Synthesis, functionalization and toxicity of multicolour bifunctional nanophosphors. JCPR, 16, 59 .

Terraschke, H., Suta, M., Adlung, M., Mammadova, S., Musayeva, N., Jabbarov, R., ... Wickleder, C. (2015b). $\operatorname{SrAl}_{2} \mathrm{O}_{4}: \mathrm{Eu}^{2+}$ (, Dy ${ }^{3+}$ ) nanosized particles: synthesis and interpretation of temperature-dependent optical properties. Journal of Spectroscopy, 2015, 1-12.

Terraschke, H., Ruiz Arana, L., Lindenberg, P., \& Bensch, W. (2016). Development of a new in-situ analysis technique applying luminescence of local coordination sensors: principle and application for monitoring metal-ligand exchange processes. Analyst, 141, 2588-2594.

Terraschke, H., Rothe, M., Tsirigoni, A.-M., Lindenberg, P., Ruiz Arana, L., Heidenreich, N., ... Etter, M. (2017). In-situ luminescence analysis: a new light on monitoring calcium phosphate phase transitions. Inorganic Chemistry Frontiers, 4, 1157-1165.

Veligzhanin, A. A., Zubavichus, Y. V., Kozitsyna, N. Y., Murzin, V. Y., Khramov, E. V., \& Chernyshov, A. A. (2013). Investigation of PdZn nanoparticle formation upon the thermal decomposition of acetate precursors by in-situ XRD and XAFS. Journal of Surface Investigation: X-ray, Synchrotron and Neutron Techniques, 7, 422-433. 
Vergote, G. J., Vervaet, C., Remon, J. P., Haemers, T., \& Verpoort, F. (2002). Near-infrared FT-Raman spectroscopy as a rapid analytical tool for the determination of diltiazem hydrochloride in tablets. European Journal of Pharmaceutical Sciences, 16, 63-67.

Vistad, O. B., Akporiaye, D. E., Taulelle, F., \& Lillerud, K. P. (2003). In Situ NMR of SAPO-34 Crystallization. Chemistry of Materials, 15, 1639-1649.

Walton, R. I., \& O'Hare, D. (2000). Watching solids crystallise using in situ powder diffraction. Chemical Communications, $23,2283-2291$.

Walton, R. I., \& Millange, F. (2016). In-situ studies of the crystallisation of metal-organic frameworks. In S. Kaskel (Ed.), The chemistry of metalorganic frameworks: synthesis, characterization, and applications. Weinheim, Germany: Wiley-VCH.

Wu, Y., Breeze, M. I., Clarkson, G. J., Millange, F., O'Hare, D., \& Walton, R. I. (2016a). Exchange of coordinated solvent during crystallisation of a metal-organic framework observed by in-situ high energy X-ray diffraction. Angewandte Chemie International Edition, 55, $4992-4996$.

Wu, Y., Henke, S., Kieslich, G., Schwedler, I., Yang, M., Fraser, D. A. X., \& O'Hare, D. (2016b). Time-resolved in-situ X-ray diffraction reveals metal-dependent metal-organic framework formation. Angewandte Chemie International Edition, 55, 14081-14084.

Yao, T., Sun, Z., Li, Y., Pan, Z., Wei, H., Xie, Y., ... Wei, S. (2010). Insights into initial kinetic nucleation of gold nanocrystals. Journal of the American Chemical Society, 132, 7696-7701.

Yao, T., Liu, S., Sun, Z., Li, Y., He, S., Cheng, H., ... Wei, S. (2012). Probing nucleation pathways for morphological manipulation of platinum nanocrystals. Journal of the American Chemical Society, 134, 9410-9416.

Yen, W. M., Yamamoto, H., Shionoya, S. (2006). Phosphor handbook, laser and optical science and technology. Boca Raton, FL: CRC Press.

Yeung, H. H.-M., Wu, Y., Henke, S., Cheetham, A. K., O'Hare, D., \& Walton, R. I. (2016). In-situ observation of successive crystallizations and metastable intermediates in the formation of metal-organic frameworks. Angewandte Chemie International Edition, 55, $2012-2016$.

Zadesenets, A. V., Asanova, T. I., Vikulova, E. S., Filatov, E. Y., Plyusnin, P. E., Baidina, I. A., ... Korenev, S. V. (2013). Solid solutions of platinum(II) and palladium(II) oxalato-complex salt as precursors of nanoalloys. Journal of Solid State Chemistry, 199, 71-77. 